\title{
Project Portfolio Resource Risk Assessment considering Project Interdependency by the Fuzzy Bayesian Network
}

\author{
Libiao Bai $\mathbb{D}^{1,2}$ Kaimin Zhang $\left(\mathbb{D},{ }^{1}\right.$ Huijing Shi $\mathbb{D}^{1},{ }^{1}$ Min An $\mathbb{D}^{3},{ }^{3}$ and Xiao Han $\mathbb{D}^{1}$ \\ ${ }^{1}$ School of Economics and Management, Chang'an University, Xi'an, Shaanxi 710064, China \\ ${ }^{2}$ Research Center for Green Engineering and Sustainable Development, Chang'an University, \\ Middle-section of Nan'er Huan Road, Xi'an 710064, China \\ ${ }^{3}$ School of Science, Engineering and Environment, University of Salford, Manchester M5 4WT, UK \\ Correspondence should be addressed to Kaimin Zhang; kaimin.zhang@chd.edu.cn
}

Received 9 July 2020; Revised 16 September 2020; Accepted 30 September 2020; Published 5 November 2020

Academic Editor: Guangdong Wu

Copyright (C) 2020 Libiao Bai et al. This is an open access article distributed under the Creative Commons Attribution License, which permits unrestricted use, distribution, and reproduction in any medium, provided the original work is properly cited.

\begin{abstract}
Resource risk caused by specific resource sharing or competition among projects due to resource constraints is a major issue in project portfolio management, which challenges the application of risk analysis methods effectively. This paper presents a methodology by using a fuzzy Bayesian network to assess the project portfolio resource risk, determine critical resource risk factors, and propose risk-reduction strategies. In this method, the project portfolio resource risk factors are first identified by taking project interdependency into consideration, and then the Bayesian network model is developed to analyze the risk level of the identified risk factors in which expert judgments and fuzzy set theory are integrated to determine the probabilities of all risk factors to deal with incomplete risk data and information. To reduce the subjectivity of expert judgments, the expert weights are determined by combining experts' background and reliability degree of expert judgments. A numerical analysis is used to demonstrate the application of the proposed methodology. The results show that project portfolio resource risks can be analyzed effectively and efficiently. Furthermore, "poor communication and cooperation among projects," "capital difficulty," and "lack of sharing technology among projects" are considered the leading factors of the project portfolio resource risk. Risk-reduction strategic decisions based on the results of risk assessment can be made, which provide project managers with a useful method or tool to manage project risks.
\end{abstract}

\section{Introduction}

A project portfolio (PP) refers to managing projects, programs, subportfolios, and operations to achieve strategic objectives [1], which is regarded as a dynamic system with inherent characteristics such as multicomponent interaction [2] and complex internal and external environments. Such unique features increase the complexities and uncertainties of the PP and generate various risks in turn. The resource sharing and competition among multiple managers to achieve their respective project goals in the resource-limited environment further exacerbate the complexity of resource management $[3,4]$. For such cases, inappropriate management of these resources can lead to the project portfolio resource risk (PPRR) and PP failure. It is necessary to consider both the characteristics of the project itself and the project interdependency [5]. In this paper, PPRR is defined as the risk caused by unreasonable allocation and unqualified quality of resources, such as human, equipment, and materials, as well as the sharing/competition of specific resources among projects during the implementation of the PP. To ensure the effective implementation of the PP, early and effective identification and assessment of the PPRR are essential.

Fault tree analysis (FTA), event tree analysis (ETA), failure mode effect analysis (FMEA), and Bayesian network (BN) have been widely applied [6] in quantitative risk analysis. However, most of these methods are known to be static and unable to capture risk variation as change occurs [7]. In addition, these methods use generic failure data that may introduce uncertainty into the results [8]. Compared with these methods, $\mathrm{BN}$ is a more flexible modeling 
approach for conducting dynamic risk analysis. $\mathrm{BN}$ is also a probability inference method for reasoning under uncertainty and supports an efficient evidence propagation mechanism that helps to update the probability of risk factors [9]. Moreover, the dynamic nature and uncertainty of the PPRR can be considered clearly through the BN. Thus, this study utilizes the BN to quantify and assess the PPRR.

This study first focuses on identifying resource risk factors considering project interdependency. Second, PPRR assessment is performed based on the fuzzy Bayesian network (FBN) model proposed by Zarei et al. [10]. This model integrates expert judgments and fuzzy set theory into the $\mathrm{BN}$ to improve the accuracy of probability acquisition. Finally, the probability of the PPRR is estimated, and the critical risk factors are identified through propagation analysis and sensitivity analysis, respectively. On this basis, corresponding risk-reduction strategies are proposed to provide powerful support for project managers to make management decisions.

The structure of this paper is organized as follows. The literature pertaining to resource risk management and $\mathrm{BN}$ based risk analysis is presented in Section 2. The steps of BN model construction are shown in Section 3. The application of the BN model is illustrated in Section 4, and the results of propagation analysis and sensitivity analysis are also presented. The discussion and suggestions are presented in Section 5, and the conclusions derived from this paper are summarized in Section 6.

\section{Literature Review}

This section consists of two main parts. The current status of resource risk management is presented in Section 2.1, and Section 2.2 describes the application of the BN approach in risk analysis to demonstrate the advantages of the $\mathrm{BN}$.

2.1. Resource Risk Management. Project implementation is regarded as a dynamic process of resource consumption [11], and reasonable resource allocation is important for all projects to minimize deadline delays and avoid wasted resources [12]. Nevertheless, various uncertainties during project implementation may perturb resource allocation plans and cause resource risk. Some studies have qualitatively developed resolution strategies such as establishing rational organizational structures [13] and negotiation frameworks [14] to optimize resource allocation. Most studies have also quantitatively proposed theoretical models for exploring resource-constrained project scheduling problems (RCPSPs) [15] and multimode resource-constrained project scheduling problems (MRCPSPs) [16, 17]. The aim is to minimize project duration by deciding on resource allocation and activity precedence relations. Although these studies were conducted on resource risk management, they focus on the single-project level and fail to provide insight into how to manage multiproject resource risk.

Prior work has affirmed the importance of implementing resource risk management in a multiproject environment
[18]. A fundamental perception obtained from multiproject research is that projects are often intertwined due to resource interdependency, which deteriorates work productivity [19]. Furthermore, disruptions in one project resulting from an unexpected event can trigger the failure of concurrent projects. To address these challenges, significant advances have been made that propose appropriate algorithms for scheduling resources to reduce the occurrence of the resource risk $[20,21]$. However, the algorithms used to address resource scheduling remain as challenges since these methods appear inapposite to formulate managerial practices. Therefore, several studies have analyzed resource conflict problems during multiproject implementation and proposed countermeasures to prevent the resource conflict [22-24]. On the whole, these studies have investigated resource risk management at a multiproject level, but they did not pay sufficient attention to the systematic identification, assessment, and response of the resource risk to avoid blindness in multiproject risk management. There is an urgent need to comprehensively evaluate the resource risk.

Although most studies have conducted resource risk management qualitatively and quantitatively, few have examined resource risk quantitatively from the perspective of systematic identification, assessment, and response. Moreover, resource risk assessment considering project interdependency in a multiproject environment has not been mentioned. In light of the above, this paper mainly identifies resource risk factors considering project interdependency and performs PPRR assessment via the use of the $\mathrm{BN}$ method.

2.2. BN-Based Risk Analysis. $\mathrm{BN}$ has been used for risk analysis in software projects [25], new product development [26], and large engineering projects [27]. The application of the $\mathrm{BN}$ involves different aspects. In causal relationship analysis among risk factors, Guan and Guo [28] analyzed the interdependent relationship among risk factors and constructed a BN to evaluate the PP risk. Ghasemi et al. [29] presented a $\mathrm{BN}$ model for modeling and analyzing the PP risk considering risk interactions. Aliabadi et al. [30] constructed a $\mathrm{BN}$ to depict the causal relationship between human and organizational factors that influence mining incidents. In terms of critical factor identification, Zahra et al. [31] applied a BN model to quantify occupational safety risks and determine the top-ranking contributory factors of occupational incidents. Mohammadfam et al. [32] developed a $\mathrm{BN}$ for predicting the impact extent of influencing factors on the safety behavior of employees in the construction industry. In data uncertainty processing, Zerrouki and Smadi [33] and Javadi et al. [34] also indicated that the BN can be used to update the prior probability of an event based on the Bayesian theorem and that the updated probabilities can decrease the uncertainty and produce more realistic input for basic events.

Previous studies have denoted $\mathrm{BN}$ as a causal model and a proper tool in assessing the impact of risk factors and dealing with data uncertainty. However, the occurrence probability of risk factors in the conventional $\mathrm{BN}$ is always 
regarded as a crisp value. It is difficult to obtain exact probability values in cases of data scarcity in the PP, which can lead to inappropriate risk assessment. Fuzzy set theory (FST) has been used as a tool for handling the problems raised from crisp values and providing flexible modeling of imprecise data and information [35, 36]. Following this direction, FST has been introduced to extend the conventional BN to a fuzzy Bayesian network (FBN) [37]. Several studies have proposed some effective methods and solution approaches (see Table 1) to provide a reliable basis for probabilistic inference with uncertain information. In these studies, a critical issue of FBN inference is how to handle fuzzy information. One normal approach is to use an appropriate fuzzy approach to conduct the inference calculation. To mitigate the complexity of the inference process, many studies have converted the fuzzy parameters into crisp values before analyzing Bayesian inference. This can be accomplished through defuzzification methods such as the centre of area $(\mathrm{CoA})[38,39]$, max-min, centre of gravity [40], and $\alpha$-cut-based interval operations [41]. In summary, the need to consider fuzzy parameters and expert judgments in the reasoning process of the $\mathrm{BN}$ given the absence of sufficient data has become evident. Additionally, the common findings of the above studies demonstrate the advantages of FBNs in probability calculation. Therefore, FBN is an applicable means for improving the accuracy of probability calculation.

Given the advantages of the $\mathrm{BN}$ in modeling the causal relationship among risk factors and evaluating the probability of risk factors, adopting the $\mathrm{BN}$ model to assess the PPRR for successful PP implementation is a topic of interest in the literature. However, conventional $\mathrm{BN}$ is unable to obtain an accurate probability and leads to errors in the results. To improve the accuracy of the probability calculation, this paper applies an FBN model to assess the PPRR.

\section{Model Construction}

To systematically assess the PPRR, the risk factors are primarily identified by considering project interdependency, and the BN structure is determined accordingly. Subsequently, the probabilities of all risk factors are calculated by integrating FST with expert judgments. Finally, Bayesian inference techniques are utilized to evaluate the PPRR. The details of the PPRR assessment model are presented in Figure 1.

\subsection{Identification of Project Portfolio Resource Risk Factors.}

To establish a comprehensive PPRR assessment system, the risk factors are identified by analyzing the literature pertaining to single-project resource risk, program resource risk, and PP risk. According to the literature on the singleproject resource risk and program resource risk, specific resource risk factors are generally identified from the perspective of resource category. For example, Jiang et al. [42] divided program resource conflict risks into five categories: human, materials and equipment, capital, organization and management, and operational environment resource conflict risks. Zhou [43] divided the resources of overseas construction projects into materials, equipment, labor, capital, energy, information, technology, etc. In addition, PMI [44] indicates that project resources include team members, equipment, materials, and other resources. As a special resource, capital is the basis for acquiring other resources and conducting all project activities. Technology and information, as intellectual resources, play an important role in meeting project needs. These three resources can be considered other resources. While PP is composed of multiple projects, this paper divides all resource risk factors for PP into six categories by considering the extensive literature: (1) human; (2) equipment; (3) materials; (4) capital; (5) information; and (6) technology. Human and equipment resources are working-hour resources and can be reused, but they can only be used for one project at a time. Materials and capital resources are expendable resources. Once consumed during project implementation, they cannot be reused. Information and technology resources belong to other resources. During PP implementation, each project will be affected by these resources, and if they cannot meet the needs of the project, the project schedule may be affected. Based on the six determined resource categories, the associated risk factors are identified according to the characteristics of different resources. However, compared with a single project, there are complex interdependencies among projects in the PP. When identifying these risk factors, project interdependency needs to be considered. Therefore, the associated risk factors are identified from two perspectives on the basis of six kinds of resources: (1) portfolio-level risk factors and (2) risk factors arising from project interdependency. It is worth noting that the R64 factor "lack of sharing technology among projects" is proposed by the authors of this study because the authors believe that "lack of sharing technology among projects" is an important reason for the occurrence of the PPRR. In the implementation of the PP, projects are interrelated because of shared resources. If two projects share resources, then lack of shared resources may pose a threat to the success of both projects. Technology as an intellectual resource: the lack of sharing technology among projects will cause a project to fail or even the entire $\mathrm{PP}$ to fail. Therefore, $R 64$ is listed as one of the resource risk factors. The detailed risk factors are presented in Table 2 .

3.2. Structure of the Bayesian Network. A BN is a directed acyclic graph and consists of a series of nodes and edges representing variables and their conditional dependencies, respectively [56]. Each node in a $\mathrm{BN}$ is assigned a probability distribution, while each edge is affiliated with a direction, which is directed from one node (parent) to another node (child). The root nodes that have no parent nodes are assigned with prior probability values. The intermediate/leaf nodes that have parent nodes are assigned to the conditional probability tables (CPTs). Considering the conditional dependencies of variables and the chain rules, a $\mathrm{BN}$ represents the joint probability distribution $P(U)$ of a set of variables $U=\left\{X_{1}, \ldots, X_{n}\right\}$ as follows: 
TABLE 1: Related work on the fuzzy Bayesian network.

\begin{tabular}{lcccc}
\hline Source & Fuzzy parameter & Fuzzy approach & Defuzzification method & Application \\
\hline $\begin{array}{l}\text { Li et al. (2019) } \\
\begin{array}{l}\text { Dolatabad and Azar } \\
\text { (2019) }\end{array}\end{array}$ & $\begin{array}{c}\text { Triangular fuzzy number } \\
\text { Zarei et al. (2019) }\end{array}$ & $\begin{array}{c}\text { Fuzzy analytic } \\
\text { hierarchy process }\end{array}$ & $\begin{array}{c}\text { Centre of gravity } \\
\text { Trapezoidal fuzzy number }\end{array}$ & $\begin{array}{c}\text { Risk assessment of mine ignition } \\
\text { sources }\end{array}$ \\
$\begin{array}{l}\text { Zhou et al. (2018) } \\
\text { Triangular and trapezoidal } \\
\text { fuzzy number }\end{array}$ & $\begin{array}{c}\text { Fuzzy logic theory } \\
\text { Fuzzy logic theory }\end{array}$ & CoA & CoA & $\begin{array}{c}\text { Safety analysis of process systems } \\
\text { Human reliability analysis in the } \\
\text { shipping industry }\end{array}$ \\
\hline
\end{tabular}

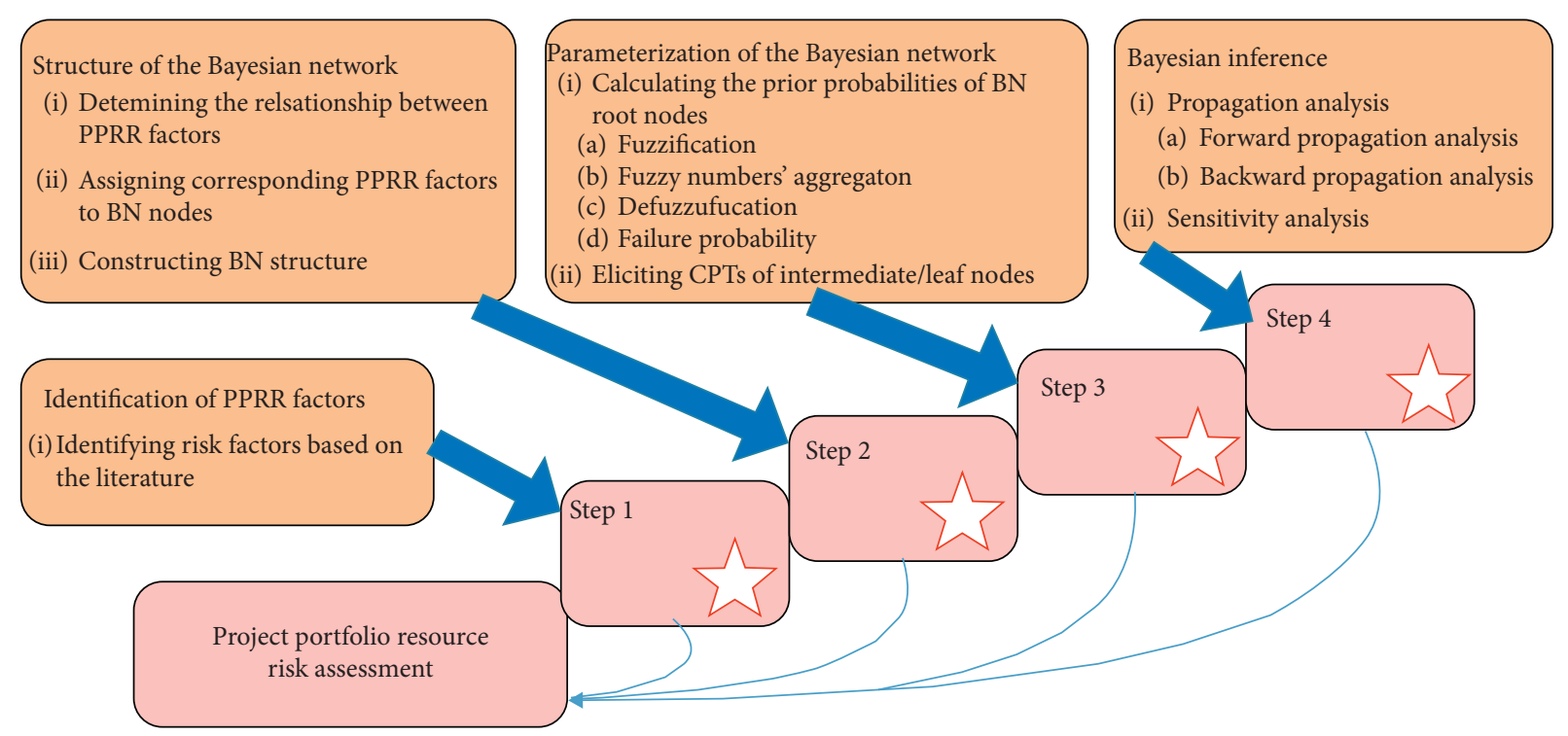

FIGURE 1: The workflow of project portfolio resource risk assessment.

$$
P(U)=\prod_{i=1}^{n} P\left(X_{i} \mid P_{\alpha}\left(X_{i}\right)\right),
$$

where $P_{\alpha}\left(X_{i}\right)$ is the parent set of variable $X_{i}$ and $n$ represents the total number of variables. Accordingly, the marginal probability of $X_{i}$ is calculated as follows:

$$
P\left(X_{i}\right)=\sum_{X_{j}, j \neq i} P(U) .
$$

$\mathrm{BN}$ uses the Bayes theorem to estimate updated (posterior) probabilities of events given new observations, called evidence $(E)$, as presented in equation (3). This evidence can occur in the form of near misses, mishaps, incidents, or observations of the consequences of the accident that become available during the lifecycle of a process.

$$
P(U \mid E)=\frac{P(U, E)}{P(E)}=\frac{P(U, E)}{\sum_{U} P(U, E)} .
$$

3.3. Parameterization of the Bayesian Network. The parameterization refers to calculating the prior probabilities of the root nodes and the CPTs for the intermediate/leaf nodes. To improve the accuracy of the probability calculation, a fuzzy probability method combining expert judgments and
FST according to Zarei et al. [10] is applied to compute the probabilities of all nodes. The detailed calculation processes of prior probabilities and CPTs are shown as follows.

3.3.1. Prior Probabilities of Root Nodes. The calculation processes of prior probabilities consist of four steps as follows.

\section{Step 1. Fuzzification:}

Suppose that every expert expresses his or her judgments about the probabilities of root nodes by using a predefined set of linguistic variables. Fuzzification is used to convert linguistic variables to corresponding fuzzy numbers. To obtain this transformation criterion, the linguistic variables and their corresponding fuzzy numbers developed by Chen and Hwang [57] are chosen to compute the probabilities of all root nodes. Table 3 presents fuzzy numbers in the form of trapezoidal fuzzy numbers used in this study.

Step 2. Fuzzy numbers' aggregation:

After expert judgments are transformed into corresponding trapezoidal fuzzy numbers, various methods are used to aggregate expert judgments such as fuzzy priority relations, game theory, max-min Delphi method, and similar aggregation method (SAM) [10]. In this study, experts are employed to estimate the occurrence probabilities of risk 
TABLE 2: Project portfolio resource risk factors.

\begin{tabular}{|c|c|c|c|}
\hline Risk category & Risk factor & Description & Reference \\
\hline \multirow{5}{*}{$\begin{array}{l}\text { Human resource } \\
\text { risk }(R 1)\end{array}$} & $\begin{array}{l}\text { Insufficient technicians and } \\
\text { managers }(R 11)\end{array}$ & $\begin{array}{c}\text { The organization does not employ technicians and managers } \\
\text { based on the needs of the PP. }\end{array}$ & [42] \\
\hline & $\begin{array}{l}\text { Unreasonable configuration of } \\
\quad \text { related personnel }(R 12)\end{array}$ & $\begin{array}{l}\text { The organization does not arrange appropriate personnel to } \\
\text { complete the specific tasks. }\end{array}$ & {$[42]$} \\
\hline & $\begin{array}{l}\text { Improper competencies of } \\
\text { technicians and managers }(R 13)\end{array}$ & $\begin{array}{c}\text { Technicians and managers lack appropriate competencies to } \\
\text { complete the tasks. }\end{array}$ & [45-47] \\
\hline & $\begin{array}{l}\text { Lack of related personnel liquidity } \\
\text { among projects }(R 14)\end{array}$ & $\begin{array}{l}\text { The cross-project liquidity among related personnel is poor in the } \\
\text { PP. }\end{array}$ & {$[29]$} \\
\hline & $\begin{array}{l}\text { Poor communication and } \\
\text { cooperation among projects }(R 15)\end{array}$ & $\begin{array}{l}\text { The cross-project communication and cooperation between } \\
\text { managers or technicians are poor in the PP. }\end{array}$ & [45-48] \\
\hline \multirow{4}{*}{$\begin{array}{l}\text { Equipment resource } \\
\text { risk }(R 2)\end{array}$} & $\begin{array}{c}\text { Untimely supply of equipment } \\
(R 21)\end{array}$ & The supply of equipment is later than expected in the plan. & {$[42]$} \\
\hline & $\begin{array}{l}\text { Unreasonable configuration of } \\
\text { equipment }(R 22)\end{array}$ & The equipment is not organized according to the needs of the PP. & {$[42]$} \\
\hline & $\begin{array}{l}\text { Instability of equipment } \\
\text { performance }(R 23)\end{array}$ & $\begin{array}{l}\text { The equipment specifications do not meet the expected } \\
\text { requirements. }\end{array}$ & {$[42]$} \\
\hline & $\begin{array}{l}\text { Lack of general equipment } \\
\text { liquidity among projects }(R 24)\end{array}$ & The cross-project liquidity of general equipment is poor in the PP. & [29] \\
\hline \multirow{5}{*}{$\begin{array}{l}\text { Materials resource } \\
\text { risk }(R 3)\end{array}$} & Untimely supply of materials $(R 31)$ & The supply of materials is later than expected in the plan. & [42] \\
\hline & $\begin{array}{c}\text { Unreasonable configuration of } \\
\text { materials }(R 32)\end{array}$ & The materials are not organized according to the needs of the PP. & {$[42]$} \\
\hline & $\begin{array}{l}\text { Unqualified materials' quality } \\
\qquad(R 33)\end{array}$ & $\begin{array}{c}\text { The materials' quality and specifications do not meet the expected } \\
\text { requirements. }\end{array}$ & {$[42]$} \\
\hline & $\begin{array}{l}\text { Lack of turnover materials' } \\
\text { liquidity among projects }(R 34)\end{array}$ & The cross-project liquidity of turnover materials is poor in the PP. & [29] \\
\hline & Capital difficulty $(R 41)$ & The sources of obtaining capital are limited. & {$[45-47]$} \\
\hline \multirow{2}{*}{$\begin{array}{l}\text { Capital resource risk } \\
(R 4)\end{array}$} & $\begin{array}{l}\text { Unreasonable configuration of } \\
\text { capital }(R 42)\end{array}$ & $\begin{array}{l}\text { The configuration of capital is not in accordance with the priority } \\
\text { order of projects. }\end{array}$ & {$[42]$} \\
\hline & $\begin{array}{l}\text { Lack of capital liquidity among } \\
\text { projects }(R 43)\end{array}$ & The cross-project liquidity of capital is poor in the PP. & {$[45-47]$} \\
\hline \multirow{4}{*}{$\begin{array}{l}\text { Information } \\
\text { resource risk ( } R 5)\end{array}$} & Inaccurate information $(R 51)$ & $\begin{array}{c}\text { The information conveyed during PP implementation loses } \\
\text { authenticity and accuracy. }\end{array}$ & {$[29]$} \\
\hline & $\begin{array}{l}\text { Information transmission delay } \\
\text { among projects }(R 52)\end{array}$ & Information is not delivered timely in the PP. & {$[45-47]$} \\
\hline & $\begin{array}{l}\text { Information asymmetry among } \\
\text { projects }(R 53)\end{array}$ & $\begin{array}{l}\text { Information asymmetry means that the amount of information } \\
\text { owned by project managers is different. Project managers who } \\
\text { own little information may make wrong decisions. }\end{array}$ & [42] \\
\hline & $\begin{array}{l}\text { Lack of sharing information } \\
\text { among projects }(R 54)\end{array}$ & $\begin{array}{c}\text { Information exchange and information sharing are poor among } \\
\text { projects. }\end{array}$ & {$[29,45-47]$} \\
\hline \multirow{4}{*}{$\begin{array}{l}\text { Technology } \\
\text { resource risk }(R 6)\end{array}$} & Weak technology maturity (R61) & $\begin{array}{l}\text { Weak technology maturity refers to a large gap between the } \\
\text { existing technology and the technology needed to achieve project } \\
\text { objectives that could cause PP schedule delay. }\end{array}$ & {$[49-52]$} \\
\hline & Slow technology update (R62) & $\begin{array}{l}\text { The rate of improvement/update from the existing technology to } \\
\text { the new technology is slow in the PP. }\end{array}$ & {$[53]$} \\
\hline & Technology changes (R63) & $\begin{array}{l}\text { Technology (e.g., process flow and design drawings) incurs } \\
\text { significant changes in the PP. }\end{array}$ & {$[54,55]$} \\
\hline & $\begin{array}{l}\text { Lack of sharing technology among } \\
\text { projects }(R 64)\end{array}$ & $\begin{array}{l}\text { Technology communication and technology sharing are poor } \\
\text { among projects. If two projects share technology, then a lack of } \\
\text { sharing of technology may pose a threat to the success of both } \\
\text { projects. }\end{array}$ & Authors \\
\hline
\end{tabular}

TABLE 3: Linguistic variables and corresponding trapezoidal fuzzy members.

\begin{tabular}{lc}
\hline Linguistic variables & Trapezoidal fuzzy members \\
\hline Very low & $(0,0,0,0.2)$ \\
Low & $(0,0.2,0.2,0.4)$ \\
Medium & $(0.3,0.5,0.5,0.7)$ \\
High & $(0.6,0.8,0.8,1)$ \\
Very high & $(0.8,1,1,1)$ \\
\hline
\end{tabular}

factors. To reduce the subjectivity of expert judgments, the expert weights are calculated by combining experts' background and reliability degree of expert judgments, which can be accomplished by the SAM approach. Thus, in this study, SAM is employed to aggregate trapezoidal fuzzy numbers obtained from experts into one trapezoidal fuzzy number. The computational processes of the SAM are provided in detail using the following 5 steps: 
(1) Calculate the degree of similarity. $S_{u v}\left(\widetilde{R}_{u}, \widetilde{R}_{v}\right)$ is defined as the degree of agreement between each pair of experts $E_{u}$ and $E_{v} \quad\left(E_{u, v}(u, v=1,2, \ldots, m)\right)$. Suppose $\widetilde{R}_{u}=a_{1}, a_{2}, a_{3}, a_{4}$ and $\widetilde{R}_{v}=\left(b_{1}, b_{2}, b_{3}, b_{4}\right)$ are two standard trapezoidal fuzzy numbers obtained from experts $E_{u}$ and $E_{v}(u \neq v)$; the degree of similarity $S_{u v}$ is defined by

$S_{u v}\left(\widetilde{R}_{u}, \widetilde{R}_{v}\right)=1-\frac{1}{J} \sum_{i=1}^{J}\left|a_{i}-b_{i}\right|, \quad i=1,2,3,4$.

When $S_{u v}\left(\widetilde{R}_{u}, \widetilde{R}_{v}\right)$ is in the interval $[0,1]$, the greater the values of $S_{u v}\left(\widetilde{R}_{u}, \widetilde{R}_{v}\right)$ are, the better the similarity between experts $E_{u}$ and $E_{v}$ is. $J$ is the number of fuzzy set members, meaning that trapezoidal fuzzy numbers should be 4 .

(2) Calculate the average agreement $\operatorname{AA}\left(E_{u}\right)$ degree for each expert judgment:

$$
\operatorname{AA}\left(E_{u}\right)=\frac{1}{m-1} \sum_{u \neq v}^{m} S_{u v, v=1, m}\left(\widetilde{R}_{u}, \widetilde{R}_{v}\right),
$$

where $m$ is the total number of experts.

(3) Calculate the relative agreement $\operatorname{RA}\left(E_{u}\right)$ degree for each expert:

$$
\operatorname{RA}\left(E_{u}\right)=\frac{\operatorname{AA}\left(E_{u}\right)}{\sum_{u=1}^{m} \operatorname{AA}\left(E_{u}\right)} .
$$

(4) Estimate the consensus coefficient $\operatorname{CC}\left(E_{u}\right)$ degree for each expert:

$$
\begin{gathered}
\mathrm{CC}\left(E_{u}\right)=\beta W\left(E_{u}\right)+(1-\beta) \operatorname{RA}\left(E_{u}\right) \\
\mathrm{WS}\left(E_{u}\right)=S_{E_{u}}(\mathrm{PP})+S_{E_{u}}(\mathrm{ET})+S_{E_{u}}(\mathrm{EL})+S_{E_{u}}(A), \\
W\left(E_{u}\right)=\frac{\mathrm{WS}\left(E_{u}\right)}{\sum_{u=1}^{m} \mathrm{WS}(E u)} .
\end{gathered}
$$

$W\left(E_{u}\right)$ is the background weight of each expert and is obtained by using equations (8) and (9). The coefficient $\beta(0 \leq \beta \leq 1)$ is represented as a relaxation factor to illustrate the importance of $W\left(E_{u}\right)$ over
$\operatorname{RA}\left(E_{u}\right)$. When $\beta=0$, no weight is given to $W\left(E_{u}\right)$, indicating that a homogenous group of experts is employed; in contrast, $\beta=1$ signifies that the consensus coefficient degree among the different expert judgments is high enough. WS $\left(E_{u}\right)$ is the weight score of each expert, $P P$ is the professional position, $E T$ is the experience time, EL is the education level, and $A$ is the age of each expert.

(5) Calculate the aggregated result of the experts' judgments. The aggregated result denoted by $\widetilde{R}_{A G}$ can be calculated by the following equation:

$$
\widetilde{R}_{A G}=\operatorname{CC}\left(E_{1}\right) \times \widetilde{R}_{1}+\operatorname{CC}\left(E_{2}\right) \times \widetilde{R}_{2}+\cdots+\operatorname{CC}\left(E_{m}\right) \times \widetilde{R}_{m} .
$$

Step 3. Defuzzification:

The defuzzification procedure that transfers the aggregated trapezoidal fuzzy number into the aggregated value (AV) is important for the application of FST. The centre of area (CoA) is widely used for defuzzification [58], which is expressed as the following equation:

$$
\mathrm{AV}=\frac{\int \mu_{i}(x) x d_{x}}{\int \mu_{i}(x) d_{x}}
$$

where AV represents the defuzzification result, $\mu_{i}(x)$ is the aggregated membership function, and $x$ is the output variable.

The membership function $\mu_{i}(x)$ for trapezoidal fuzzy numbers can be defined as

$$
\mu_{i}(x)=\left\{\begin{array}{cc}
0, & x<a_{1} \\
\frac{x-a_{1}}{a_{2}-a_{1}}, & a_{1} \leq x \leq a_{2} \\
1, & a_{2} \leq x \leq a_{3} \\
\frac{a_{4}-x}{a_{4}-a_{3}} & a_{3} \leq x \leq a_{4} \\
0, & x>a_{4}
\end{array}\right\} .
$$

Using equations (11) and (12), defuzzification of the aggregated trapezoidal fuzzy number $\widetilde{R}_{A G}=\left(a_{1}, a_{2}, a_{3}, a_{4}\right)$ is computed.

$$
\mathrm{AV}=\frac{\int_{a 1}^{a 2} x-a_{1} / a_{2}-a_{1} x d_{x}+\int_{a 2}^{a 3} x d_{x}+\int_{a 3}^{a 4} a_{4}-x / a_{4}-a_{3} d_{x}}{\int_{a 1}^{a 2} x-a_{1} / a_{2}-a_{1} x d_{x}+\int_{a 2}^{a 3} d_{x}+\int_{a 3}^{a 4} a_{4}-x / a_{4}-a_{3} d_{x}}=\frac{1}{3} \times \frac{\left(a_{4}+a_{3}\right)^{2}-a_{4} a_{3}-\left(a_{1}+a_{2}\right)^{2}+a_{1} a_{2}}{\left(a_{4}+a_{3}-a_{1}-a_{2}\right)}
$$


To convert AV into failure probability (FP), the following equations (14) and (15) proposed by Onisawa [59] are employed:

$$
\begin{gathered}
F P=\left\{\begin{array}{cc}
\frac{1}{10^{K}} & \text { if } \mathrm{AV} \neq 0 \\
0 & \text { if } \mathrm{AV}=0
\end{array}\right\}, \\
K=\left[\left(\frac{1-\mathrm{AV}}{\mathrm{AV}}\right)\right]^{1 / 3} \times 2.301,
\end{gathered}
$$

where $K$ is a constant value.

Finally, the calculated FP is treated as the prior probability of each root node in the developed $\mathrm{BN}$ model.

3.3.2. CPTs of Intermediate/Leaf Nodes. On the basis of the prior probability calculation, the noisy-OR gate model is utilized to implement the CPT elicitation. With the hypothesis of binary nodes in the $\mathrm{BN}$, the noisy-OR gate model is particularly applicable for a child node with multiple parent nodes. Assume a child node $Y$ has $n$ parents $X_{1}, X_{2}, \ldots, X_{i}, \ldots, X_{n}$; the states of all nodes are defined as "yes" or "no," respectively, indicating whether a variable occurs or not. The probability of $Y$ under the condition of $X_{i}$ can be obtained by

$$
P\left(Y \longleftarrow X_{i}\right)=P\left(Y \mid \bar{X}_{1}, \bar{X}_{2}, \ldots, X_{i}, \ldots, \bar{X}_{n}\right)
$$

where $\bar{X}_{i}$ represents that the state of $X_{i}$ is "no." The conditional probability of $Y$ can be calculated by

$$
P(Y \longleftarrow X)=1-\Pi_{X_{i} \in X}\left(1-P\left(Y \longleftarrow X_{i}\right)\right) .
$$

$P(Y \longleftarrow X)$ can be obtained from expert judgments, and the calculation process is illustrated in Section 3.3.1. Then, the CPT of child node $Y$ can be calculated according to equation (17).

3.4. Bayesian Inference. After the probabilities of all nodes are calculated, Bayesian inference can be performed via propagation analysis and sensitivity analysis. The propagation analysis includes two parts: forward propagation analysis and backward propagation analysis. Forward propagation analysis involves a reasoning process from the root node to the leaf node and can be used to evaluate the occurrence probability of a leaf node. Backward propagation analysis is associated with cause analysis in light of existing results, representing a reasoning process from the leaf node to the root node. Sensitivity analysis is a feasible approach that confirms the relative importance of nodes on a particular node rewarded as a target.

\section{Model Application}

In this section, the assessment of the PPRR is implemented based on the identified risk factors and the model construction steps presented in Section 3. First, a graphical model representing the causal relationship among risk factors is constructed. Second, the experts' judgments on the occurrence probabilities of all risk factors are collected by a questionnaire survey. Then, the prior probabilities and CPTs of these risk factors are calculated accordingly. Finally, propagation analysis and sensitivity analysis are employed to assess the PPRR.

4.1. Structure of the Bayesian Network. BN structure is often created through a process of expert knowledge [60], in which multiple experts are asked to give their judgments on whether there is a causal relationship among identified risk factors. By synthesizing the judgments of multiple experts on the causal relationship among identified risk factors, the $\mathrm{BN}$ model of the PPRR can be established (see Figure 2) and simulated in the GeNIe 2.3 program.

The expert judgment method has been widely applied in different fields, including risk analysis, accident investigation, decision examination, and Bayesian statistics. Expert judgment is mostly applied to accumulate experts' opinions about a subject when available data and information are insufficient or limited. Thus, expert competence is critically important for scientific conclusions. The selection principles of competent experts can be established as follows [61], and the rating criteria in Table 4 are used to score the capability of each expert.

(1) Compared with a homogenous group of experts, a heterogeneous group is generally preferred as each expert judgment has an individual weight based on his/her background and expertise

(2) Regarding the education and experience of the experts in a field, the longer they have majored in a subject, the more accurate their intuitionistic judgment is

(3) With respect to expert familiarity with a subject, especially through professional position, an experienced expert can master every detail of the subject

In this study, according to the selection principles mentioned above, a heterogeneous group of six experts is selected for calculating the occurrence probabilities of all risk factors. To improve the heterogeneity of the expert group, the selected experts in this study represent different fields associated with PP management, including a PP manager, a PP engineer, two PP senior scholars, and two experienced PP workers. These six experts passed Level $\mathrm{A}$ in the 4 -L-C system proposed by the International Project Management Association (IPMA). All of them are IPMA Level A certificate holders and named Certified Project Directors according to the IPMA. They are responsible for managing a complex PP within an organization. This study selects them as evaluators because they have mastered systematic modern project management knowledge and concepts and possessed the project management ability or the power and qualification for managing projects contained in a PP. The relevant information of six experts is summarized in detail in Table 5. 


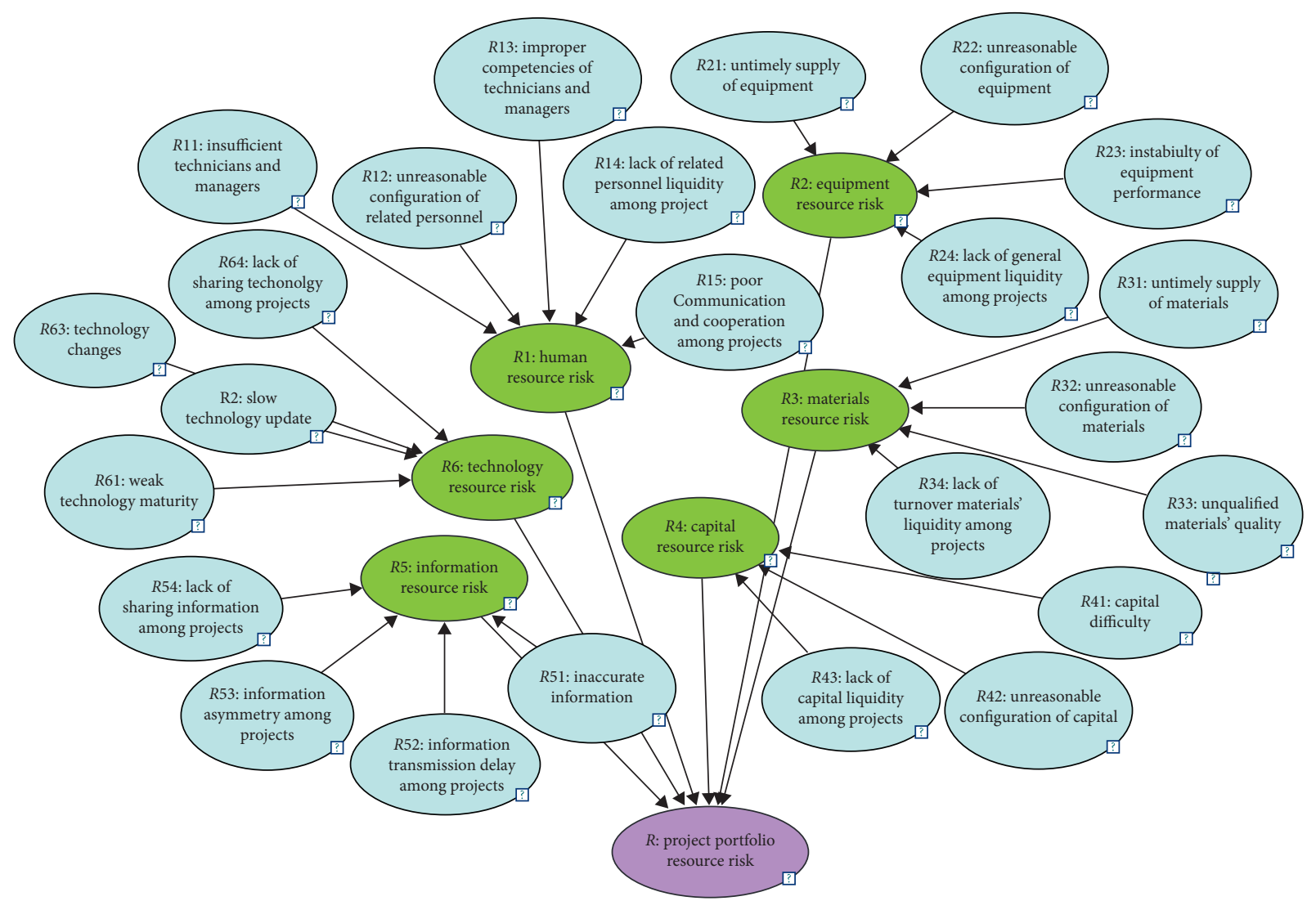

FIgURE 2: BN model of the project portfolio resource risk.

TABLE 4: Weight score of different experts.

\begin{tabular}{|c|c|c|c|c|c|}
\hline Indicator & Classification & Score & Indicator & Classification & Score \\
\hline \multirow{5}{*}{ Professional position } & Senior academic & 5 & Educational level & $\mathrm{PhD}$ & 5 \\
\hline & Junior academic & 4 & & Master & 4 \\
\hline & Engineer & 3 & & Bachelor & 3 \\
\hline & Technician & 2 & & Higher National Diploma (HND) & 2 \\
\hline & Worker & 1 & & School level & 1 \\
\hline \multirow{5}{*}{ Experience time (year) } & $\geq 30$ & 5 & Age (year) & $\geq 50$ & 4 \\
\hline & $20-29$ & 4 & & $40-49$ & 3 \\
\hline & $10-19$ & 3 & & $30-39$ & 2 \\
\hline & $6-9$ & 2 & & $<30$ & 1 \\
\hline & $\leq 5$ & 1 & & & \\
\hline
\end{tabular}

TABLE 5: Weight of different experts.

\begin{tabular}{|c|c|c|c|c|c|c|}
\hline Expert no. & Professional position & Experience time (year) & Educational level & Age (year) & Weight score & Weight \\
\hline 1 & Senior academic & $20-29$ & $\mathrm{PhD}$ & $30-39$ & $5+4+5+2=16$ & 0.213 \\
\hline 2 & Senior academic & $10-19$ & $\mathrm{PhD}$ & $30-39$ & $5+3+5+2=15$ & 0.200 \\
\hline 3 & Junior academic & $6-9$ & Master & $<30$ & $4+2+4+1=11$ & 0.147 \\
\hline 4 & Senior academic & $10-19$ & $\mathrm{PhD}$ & $30-39$ & $5+3+5+2=15$ & 0.200 \\
\hline 5 & Junior academic & $\leq 5$ & Bachelor & $<30$ & $4+1+3+1=9$ & 0.120 \\
\hline 6 & Junior academic & $\leq 5$ & Bachelor & $<30$ & $\begin{array}{c}4+1+3+1=9 \\
\text { Total }=75\end{array}$ & $\begin{array}{c}0.120 \\
\text { Total }=1\end{array}$ \\
\hline
\end{tabular}

4.2. The Prior Probabilities and CPTs of BN Nodes. After the $\mathrm{BN}$ model is developed, the probabilities for all nodes are calculated as described in Section 3.3. Table 6 gives some information concerning expert judgments for occurrence probabilities of root nodes in the forms of linguistic variables, corresponding aggregated fuzzy number, AV, and FP.

The processes of probability calculation for all root nodes are consistent. For the sake of space, "poor communication 
TABLE 6: Expert judgments for failures of root nodes in the forms of linguistic variables, corresponding aggregated fuzzy number, AV, and FP.

\begin{tabular}{|c|c|c|c|c|c|c|c|c|c|c|c|c|c|}
\hline \multirow{2}{*}{ Root nodes } & \multicolumn{6}{|c|}{ Expert judgments } & \multirow{2}{*}{\multicolumn{4}{|c|}{ Aggregated fuzzy number }} & \multirow{2}{*}{ K } & \multirow{2}{*}{$\mathrm{AV}$} & \multirow{2}{*}{$\mathrm{FP}$} \\
\hline & 1 & 2 & 3 & 4 & 5 & 6 & & & & & & & \\
\hline$R 11$ & $\mathrm{~L}$ & $\mathrm{H}$ & M & $\mathrm{L}$ & VL & M & 0.191 & 0.364 & 0.364 & 0.564 & 0.37298 & 2.73600 & 0.00184 \\
\hline$R 12$ & $\mathrm{H}$ & $\mathrm{VH}$ & $\mathrm{L}$ & VH & $\mathrm{M}$ & $\mathrm{H}$ & 0.559 & 0.759 & 0.759 & 0.883 & 0.73359 & 1.64166 & 0.02282 \\
\hline$R 13$ & $\mathrm{H}$ & $\mathrm{H}$ & $\mathrm{L}$ & $\mathrm{H}$ & $\mathrm{L}$ & $\mathrm{H}$ & 0.443 & 0.643 & 0.643 & 0.843 & 0.64343 & 1.89001 & 0.01288 \\
\hline$R 14$ & $\mathrm{VH}$ & M & VL & VH & $\mathrm{H}$ & M & 0.501 & 0.677 & 0.677 & 0.801 & 0.65972 & 1.84534 & 0.01428 \\
\hline$R 15$ & $\mathrm{H}$ & M & $\mathrm{H}$ & $\mathrm{M}$ & $\mathrm{H}$ & $\mathrm{H}$ & 0.495 & 0.695 & 0.695 & 0.895 & 0.69476 & 1.74925 & 0.01781 \\
\hline$R 21$ & M & $\mathrm{H}$ & VL & M & $\mathrm{H}$ & M & 0.359 & 0.534 & 0.534 & 0.734 & 0.54220 & 2.17482 & 0.00669 \\
\hline$R 22$ & $\mathrm{H}$ & $\mathrm{H}$ & VL & $\mathrm{H}$ & M & $\mathrm{H}$ & 0.491 & 0.669 & 0.669 & 0.869 & 0.67637 & 1.79972 & 0.01586 \\
\hline$R 23$ & $\mathrm{~L}$ & $\mathrm{~L}$ & VL & $\mathrm{L}$ & $\mathrm{L}$ & $\mathrm{L}$ & 0.000 & 0.170 & 0.170 & 0.370 & 0.18026 & 3.81221 & 0.00015 \\
\hline$R 24$ & $\mathrm{VH}$ & VH & VL & $\mathrm{M}$ & $\mathrm{VH}$ & $\mathrm{VH}$ & 0.633 & 0.813 & 0.813 & 0.868 & 0.77125 & 1.53453 & 0.02921 \\
\hline$R 31$ & $\mathrm{H}$ & $\mathrm{H}$ & $\mathrm{L}$ & M & $\mathrm{H}$ & $\mathrm{H}$ & 0.471 & 0.671 & 0.671 & 0.871 & 0.67117 & 1.81397 & 0.01535 \\
\hline$R 32$ & M & M & VL & $\mathrm{L}$ & $\mathrm{M}$ & M & 0.206 & 0.378 & 0.378 & 0.578 & 0.38717 & 2.68163 & 0.00208 \\
\hline$R 33$ & M & $\mathrm{L}$ & $\mathrm{L}$ & M & VL & $\mathrm{L}$ & 0.108 & 0.281 & 0.281 & 0.481 & 0.28989 & 3.10183 & 0.00079 \\
\hline$R 34$ & $\mathrm{~L}$ & $\mathrm{M}$ & $\mathrm{L}$ & $\mathrm{H}$ & $\mathrm{VH}$ & M & 0.314 & 0.514 & 0.514 & 0.689 & 0.50588 & 2.28303 & 0.00521 \\
\hline$R 41$ & M & $\mathrm{H}$ & $\mathrm{VH}$ & $\mathrm{H}$ & $\mathrm{H}$ & M & 0.534 & 0.734 & 0.734 & 0.904 & 0.72391 & 1.66866 & 0.02145 \\
\hline$R 42$ & $\mathrm{H}$ & $\mathrm{H}$ & $\mathrm{H}$ & $\mathrm{L}$ & M & $\mathrm{H}$ & 0.467 & 0.667 & 0.667 & 0.867 & 0.66727 & 1.82465 & 0.01497 \\
\hline$R 43$ & VH & M & $\mathrm{H}$ & M & $\mathrm{H}$ & M & 0.481 & 0.681 & 0.681 & 0.845 & 0.66892 & 1.82013 & 0.01513 \\
\hline$R 51$ & $\mathrm{M}$ & $\mathrm{L}$ & VL & M & M & M & 0.206 & 0.378 & 0.378 & 0.578 & 0.38717 & 2.68163 & 0.00208 \\
\hline$R 52$ & $\mathrm{H}$ & $\mathrm{H}$ & $\mathrm{L}$ & $\mathrm{H}$ & $\mathrm{H}$ & $\mathrm{H}$ & 0.531 & 0.731 & 0.731 & 0.931 & 0.73090 & 1.64918 & 0.02243 \\
\hline$R 53$ & $\mathrm{VH}$ & $\mathrm{H}$ & VL & M & $\mathrm{L}$ & $\mathrm{H}$ & 0.416 & 0.589 & 0.589 & 0.753 & 0.58597 & 2.04945 & 0.00892 \\
\hline$R 54$ & $\mathrm{H}$ & M & $\mathrm{L}$ & M & $\mathrm{VH}$ & $\mathrm{H}$ & 0.432 & 0.632 & 0.632 & 0.805 & 0.62297 & 1.94634 & 0.01132 \\
\hline$R 61$ & M & $\mathrm{H}$ & M & $\mathrm{L}$ & $\mathrm{L}$ & $\mathrm{M}$ & 0.254 & 0.454 & 0.454 & 0.654 & 0.45430 & 2.44599 & 0.00358 \\
\hline$R 62$ & M & $\mathrm{H}$ & $\mathrm{M}$ & M & M & $\mathrm{H}$ & 0.393 & 0.593 & 0.593 & 0.793 & 0.59324 & 2.02902 & 0.00935 \\
\hline$R 63$ & $\mathrm{~L}$ & $\mathrm{M}$ & VL & $\mathrm{L}$ & $\mathrm{M}$ & $\mathrm{L}$ & 0.094 & 0.264 & 0.264 & 0.464 & 0.27414 & 3.18332 & 0.00066 \\
\hline$R 64$ & VH & M & VL & $\mathrm{L}$ & $\mathrm{H}$ & $\mathrm{H}$ & 0.392 & 0.565 & 0.565 & 0.729 & 0.56197 & 2.11762 & 0.00763 \\
\hline
\end{tabular}

and cooperation among projects (R15)" is chosen as an example to show the calculation steps (see Table 7). To calculate the consensus coefficient (CC) (equation (7)), the relaxation factor $(\beta)$ is considered to be 0.5 according to the preference of project managers on $W\left(E_{u}\right)$ and $R A\left(E_{u}\right)$. $W\left(E_{u}\right)$ is calculated using equations (8) and (9). WS $\left(E_{u}\right)$ is computed according to Table 3, and the expert profiles and corresponding $W\left(E_{u}\right)$ are shown in Table 4 .

The CPTs of intermediate nodes and leaf nodes are elicited according to the noisy-OR gate model (equations (16) and (17)). To present the elicitation process clearly, the node "capital resource risk $(R 4)$ " with three parent nodes ( $R 41, R 42$, and $R 43)$ is taken as an example, and the detailed formation is shown in Table 8 . Table 9 gives some information concerning expert judgments for occurrence probabilities of intermediate/leaf nodes in the forms of linguistic variables.

After all the CPTs are elicited, quantitative analysis can be implemented by applying $\mathrm{BN}$ inference. Propagation analysis, one of the unique characteristics of the $\mathrm{BN}$, is critical for updating the probabilities of risk factors. Sensitivity analysis is performed to identify the most contributing risk factors for the PPRR.

4.3. Propagation Analysis. Propagation analysis is defined as a feature of the $\mathrm{BN}$ to propagate the effect of nodes through the network; this feature helps in anticipating which risk factors might affect the PPRR. Performing a forward propagation analysis on the $\mathrm{BN}$ model provides probability observations for all network nodes based on the probabilities of all nodes as calculated in Section 4.2 (see Figure 3). Under the conditions of $7 \%$ chance of "technology resource risk (R6)," 5\% chance of "capital resource risk (R4)" and "human resource risk $(R 1)$, " $4 \%$ chance of "equipment resource risk $(R 2)$ " and "information resource risk (R5)," and $2 \%$ chance of "materials resource risk (R3)," the occurrence probability of the PPRR is $17 \%$. Generally, small probability events are those whose occurrence probability is less than 5\% [40]. This paper prioritizes the occurrence probabilities of the six resource risk categories. If the initial probability of any of the six resource risk categories is larger than or equal to $5 \%$, that category is regarded as a risk that needs to be controlled, and then the corresponding critical risk factors that affect its occurrence are identified. As shown in Figure 3, the occurrence probabilities of the PPRR, "technology resource risk (R6)," "capital resource risk (R4)," and "human resource risk $(R 1)$," are all larger than $5 \%$. It is also observed that the $7 \%$ likelihood of "technology resource risk $(R 6)$ " is due to "slow technology update (R62)" and "lack of sharing technology among projects (R64)." In addition, the occurrence probabilities of "capital resource risk $(R 4)$ " and "human resource risk $(R 1)$ " are estimated to be $5 \%$. The main contributing factors are "capital difficulty (R41)" and "lack of capital liquidity among projects (R43)" and "unreasonable configuration of related personnel (R12)" and "poor communication and cooperation among projects (R15)," respectively. This approach is highly conducive for prediction and diagnostic analysis of the PPRR. 
TABLE 7: The probability calculation process for "poor communication and cooperation among projects (R15)."

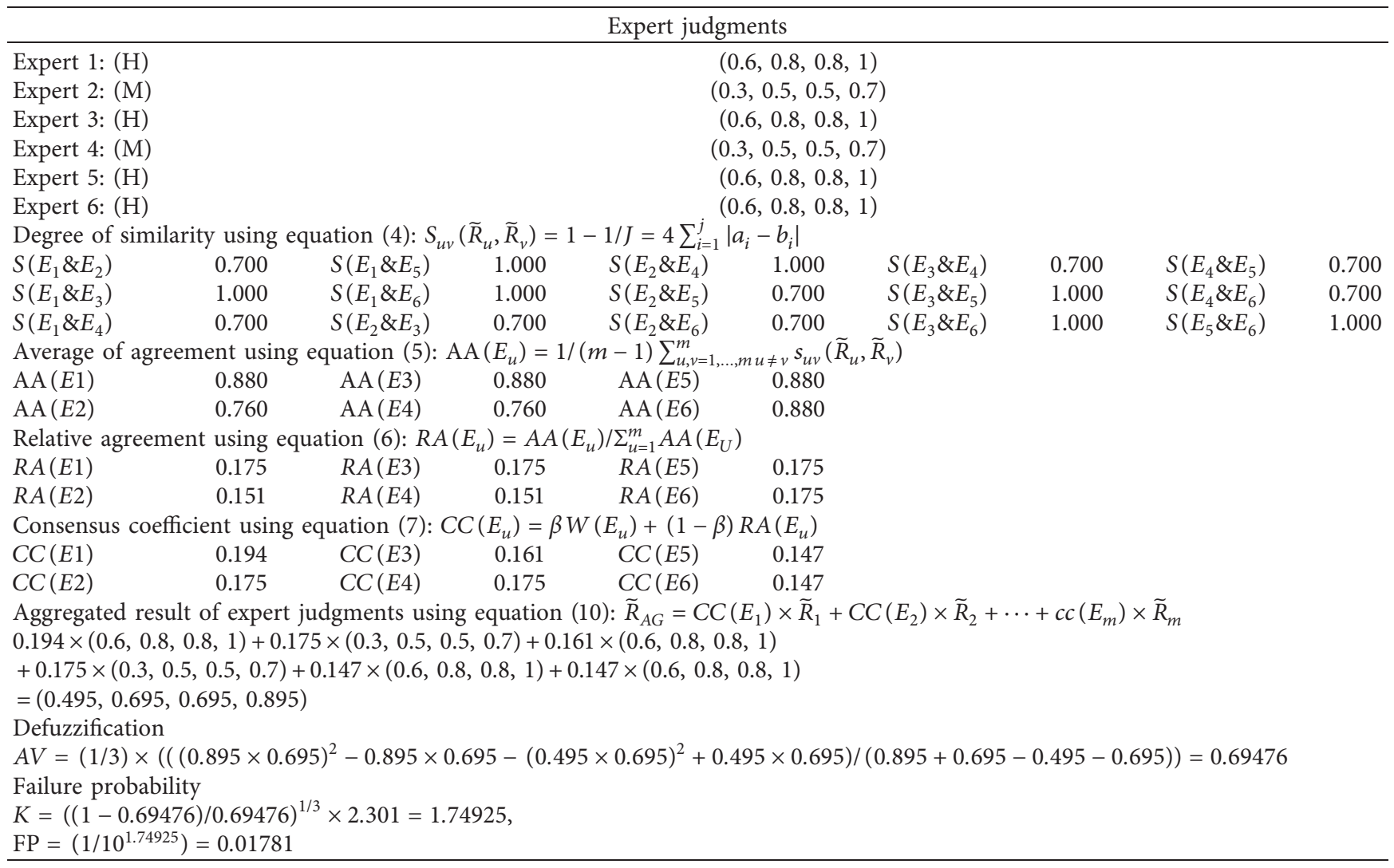

TABle 8: The CPT of the node "capital resource risk (R4)."

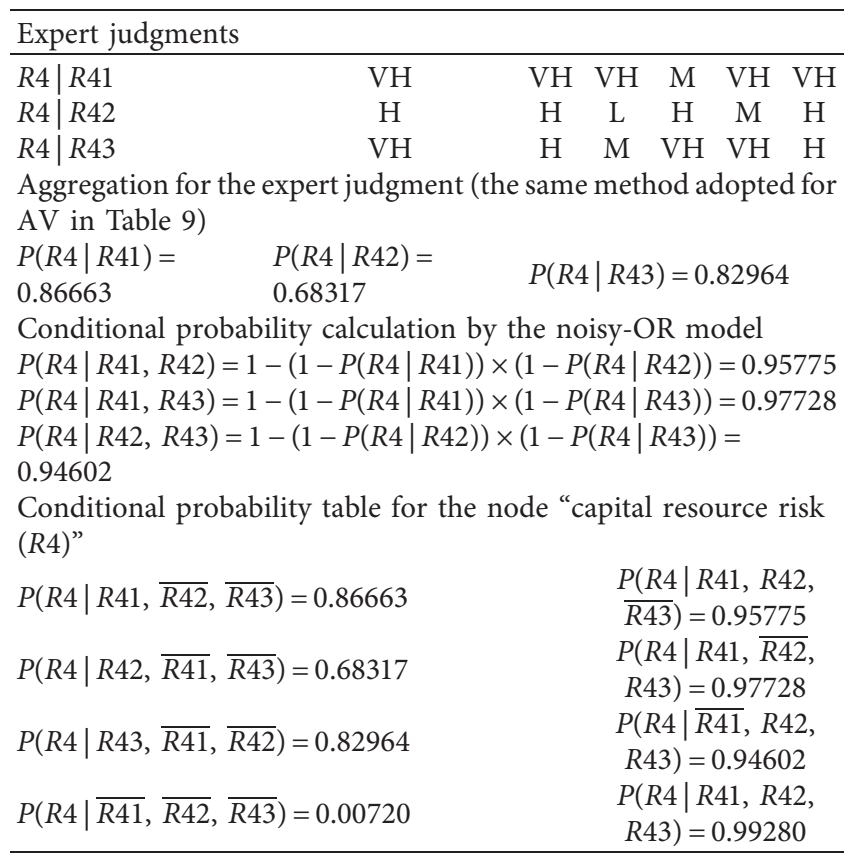

Backward propagation analysis is performed by setting the evidence for a specific/leaf node and then updates the probabilities of parent nodes by propagating the impact of the child node in a backward technique through the entire network [62]. For instance, if the occurrence probability of the PPRR is set to $100 \%$ (see Figure 4), we prioritize the consideration of resource risk categories with high posterior probabilities and then identify the critical risk factors affecting them. Figure 4 shows that "technology resource risk (R6)" increases from $7 \%$ to $25 \%$, "capital resource risk $(R 4)$ " from $5 \%$ to $26 \%$, "human resource risk $(R 1)$ " from $5 \%$ to $23 \%$, "equipment resource risk $(R 2)$ " from $4 \%$ to $18 \%$, "information resource risk (R5)" from $4 \%$ to $14 \%$, and "materials resource risk $(R 3)$ " from $2 \%$ to $10 \%$. Comparing the probabilities of these nodes, "capital resource risk $(R 4)$," "technology resource risk (R6)," and "human resource risk $(R 1)$ " are the most likely to be direct causes of the PPRR. Moreover, the occurrence probabilities of "capital difficulty (R41)," "lack of sharing technology among projects (R64)," "unreasonable configuration of related personnel (R12)," and "poor communication and cooperation among projects (R15)" all increase to a certain extent.

Based on the results of both the forward and backward propagation analysis, "unreasonable configuration of related personnel (R12)," "poor communication and cooperation among projects (R15)," "capital difficulty (R41)," and "lack of sharing technology among projects (R64)" are the critical risk factors for the PPRR.

4.4. Sensitivity Analysis. Sensitivity analysis provides an advantage in understanding which nodes have more impact on their connected nodes. To obtain an intuitionistic 
TABLE 9: Expert judgments for failures of intermediate/leaf nodes in the forms of linguistic variables.

\begin{tabular}{|c|c|c|c|c|c|c|c|}
\hline \multirow{2}{*}{ Parent node } & \multirow{2}{*}{ Risk events } & \multicolumn{6}{|c|}{ Expert judgments } \\
\hline & & $E 1$ & $E 2$ & $E 3$ & $E 4$ & E5 & E6 \\
\hline \multirow{5}{*}{$R 1$} & $R 1 \mid R 11$ & VH & $\mathrm{H}$ & M & $\mathrm{H}$ & $\mathrm{H}$ & M \\
\hline & $R 1 \mid R 12$ & $\mathrm{H}$ & $\mathrm{VH}$ & $\mathrm{L}$ & $\mathrm{L}$ & M & $\mathrm{H}$ \\
\hline & $R 1 \mid R 13$ & $\mathrm{VH}$ & $\mathrm{H}$ & $\mathrm{L}$ & $\mathrm{H}$ & $\mathrm{L}$ & $\mathrm{H}$ \\
\hline & $R 1 \mid R 14$ & $\mathrm{M}$ & M & $\mathrm{M}$ & M & $\mathrm{M}$ & M \\
\hline & $R 1 \mid R 15$ & $\mathrm{H}$ & $\mathrm{H}$ & VH & M & VH & $\mathrm{H}$ \\
\hline \multirow{4}{*}{$R 2$} & $R 2 \mid R 21$ & $\mathrm{VH}$ & $\mathrm{H}$ & $\mathrm{L}$ & M & $\mathrm{M}$ & $\mathrm{H}$ \\
\hline & $R 2 \mid R 22$ & $\mathrm{VH}$ & $\mathrm{VH}$ & M & $\mathrm{L}$ & $\mathrm{H}$ & $\mathrm{H}$ \\
\hline & $R 2 \mid R 23$ & $\mathrm{H}$ & $\mathrm{H}$ & $\mathrm{H}$ & M & $\mathrm{VH}$ & M \\
\hline & $R 2 \mid R 24$ & $\mathrm{M}$ & $\mathrm{H}$ & $\mathrm{H}$ & M & $\mathrm{M}$ & $\mathrm{H}$ \\
\hline \multirow{4}{*}{$R 3$} & $R 3 \mid R 31$ & $\mathrm{VH}$ & M & $\mathrm{H}$ & $\mathrm{H}$ & M & $\mathrm{H}$ \\
\hline & $R 3 \mid R 32$ & $\mathrm{H}$ & $\mathrm{H}$ & $\mathrm{L}$ & M & $\mathrm{H}$ & $\mathrm{M}$ \\
\hline & R3|R33 & $\mathrm{VH}$ & $\mathrm{H}$ & VH & M & $\mathrm{VH}$ & $\mathrm{VH}$ \\
\hline & $R 3 \mid R 34$ & $\mathrm{H}$ & M & VL & $\mathrm{H}$ & $\mathrm{M}$ & $\mathrm{M}$ \\
\hline \multirow{3}{*}{$R 4$} & $R 4 \mid R 41$ & $\mathrm{VH}$ & $\mathrm{VH}$ & VH & M & VH & $\mathrm{VH}$ \\
\hline & $R 4 \mid R 42$ & $\mathrm{H}$ & $\mathrm{H}$ & $\mathrm{L}$ & $\mathrm{H}$ & $\mathrm{M}$ & $\mathrm{H}$ \\
\hline & $R 4 \mid R 43$ & $\mathrm{VH}$ & $\mathrm{H}$ & M & VH & VH & $\mathrm{H}$ \\
\hline \multirow{4}{*}{ R5 } & $R 5 \mid R 51$ & $\mathrm{H}$ & M & $\mathrm{L}$ & $\mathrm{H}$ & $\mathrm{M}$ & M \\
\hline & $R 5 \mid R 52$ & $\mathrm{VH}$ & $\mathrm{H}$ & $\mathrm{L}$ & $\mathrm{H}$ & M & $\mathrm{H}$ \\
\hline & $R 5 \mid R 53$ & $\mathrm{H}$ & $\mathrm{H}$ & M & M & $\mathrm{H}$ & $\mathrm{H}$ \\
\hline & $R 5 \mid R 54$ & M & M & $\mathrm{H}$ & M & VH & M \\
\hline \multirow{4}{*}{$R 6$} & $R 6 \mid R 61$ & $\mathrm{H}$ & M & $\mathrm{L}$ & $\mathrm{L}$ & $\mathrm{H}$ & $\mathrm{H}$ \\
\hline & $R 6 \mid R 62$ & $\mathrm{~L}$ & $\mathrm{~L}$ & $\mathrm{H}$ & $\mathrm{L}$ & VL & $\mathrm{L}$ \\
\hline & $R 6 \mid R 63$ & $\mathrm{VH}$ & $\mathrm{H}$ & $\mathrm{L}$ & VL & $\mathrm{H}$ & M \\
\hline & $R 6 \mid R 64$ & $\mathrm{M}$ & $\mathrm{H}$ & $\mathrm{M}$ & $\mathrm{M}$ & $\mathrm{L}$ & $\mathrm{H}$ \\
\hline \multirow{6}{*}{$R$} & $R \mid R 1$ & $\mathrm{VH}$ & $\mathrm{VH}$ & VH & $\mathrm{H}$ & $\mathrm{H}$ & M \\
\hline & $R \mid R 2$ & $\mathrm{H}$ & $\mathrm{H}$ & $\mathrm{L}$ & M & $\mathrm{H}$ & $\mathrm{H}$ \\
\hline & $R \mid R 3$ & $\mathrm{H}$ & $\mathrm{H}$ & $\mathrm{L}$ & $\mathrm{H}$ & $\mathrm{M}$ & $\mathrm{H}$ \\
\hline & $R \mid R 4$ & $\mathrm{VH}$ & $\mathrm{VH}$ & VH & VH & VH & $\mathrm{VH}$ \\
\hline & $R \mid R 5$ & $\mathrm{M}$ & $\mathrm{M}$ & VL & $\mathrm{M}$ & $\mathrm{M}$ & M \\
\hline & $R \mid R 6$ & $\mathrm{M}$ & $\mathrm{M}$ & $\mathrm{M}$ & M & M & $\mathrm{H}$ \\
\hline
\end{tabular}

Note. $R_{i} \mid R_{i j}$ represents the possibility of $R_{i j}$ occurrence leading to $R_{i}$ occurrence. Similarly, $R \mid R_{i}$ represents the possibility of $R_{i}$ occurrence leading to $R$ occurrence.

understanding of the simulation model, the GeNIe 2.3 program is used to illustrate the degree to which the root nodes affect the leaf nodes.

To obtain the impact extent of the risk factors on the PPRR, sensitivity analysis is performed on the PPRR as a target node with respect to all risk factors. The sensitivity analysis of the PPRR is shown in Figures 5(a) and 5(b) in the form of a tornado graph. The length of the bars corresponding to each sensitivity factor in the tornado graph illustrates the impact of the corresponding factor on the PPRR [62]. Figure 5(a) illustrates the impacts of a set of risk factors on the PPRR when the PPRR is "yes." Figure 5(b) reveals the impacts of these factors when the PPRR is "no." Both figures show that "human resource risk (R1)," "capital resource risk (R4)," and "technology resource risk (R6)" have the highest impact on the PPRR. This implies that prevention of these three risks will reduce the occurrence probability of the PPRR. The sensitivity analysis of "human resource risk (R1)," "capital resource risk (R4)," and "technology resource risk (R6)" is shown in Figures 6-8. The formal representation of Figure 6 illustrates that "poor communication and cooperation among projects $(R 15)$ " has the highest impact on "human resource risk $(R 1)$." It is evident from Figure 7 that "capital difficulty (R41)" has the primary influence on "capital resource risk (R4)." Finally, Figure 8 shows that "lack of sharing technology among projects $(R 64)$ " is a contributing factor to "technology resource risk (R6)."

Combining the results of propagation analysis and sensitivity analysis, "poor communication and cooperation among projects (R15)," "capital difficulty (R41)," and "lack of sharing technology among projects (R64)" are considered key risk factors for the PPRR.

4.5. Model Validation. A Bayesian network can calculate the changed conditional probability of other risk factors by the probability change of risk factors. In this study, we measure the reduction effect of the PPRR by changing the occurrence probability of six resource risks.

Table 10 shows the probability change of PPRR through the risk reduction of six resource risks. When the occurrence probability of each resource risk is set to 0 , the PPRR level is reduced to $0.13972,0.14873,0.16045,0.13526,0.15716$, and 0.14071. Compared with the initial PPRR probability of 0.17372 , capital, human, and technology resource risks are more critical to the PPRR. Similarly, the probability changes of the above three resource risks can be obtained through the risk reduction of their specific risk factors (see Table 11). The results show that "poor communication and cooperation among projects (R15)," "capital difficulty $(R 41)$," and "lack of sharing technology among projects (R64)" are key causes of human, capital, and technology, respectively.

Moreover, another sensitivity analysis is applied to determine the $\beta$-effect on the results of the identified critical risk factors. $\beta$-values are selected as a set of $0.1,0.3,0.5,0.7$, and 0.9 which is provided in Table 12. The result of this sensitivity analysis indicates that this numerical example is not sensitive to the $\beta$-coefficient. Figure 9 illustrates that the posterior probability of six risk categories shows no notable change in different $\beta$-values, and "human resource risk $(R 1)$," "capital resource risk (R4)," and "technology resource risk (R6)" have the highest impacts on the PPRR. Similarly, the relevant risk factors affecting "human resource risk $(R 1)$," "capital resource risk (R4)," and "technology resource risk (R6)" under different $\beta$-values can be obtained from Figure 9, which are "poor communication and cooperation among projects (R15)," "capital difficulty (R41)," and "lack of sharing technology among projects (R64)," respectively. These are consistent with the results in Section 4.4, which demonstrates that the $\beta$-coefficient is not sensitive during fuzzy multiple-attribute decision-making.

\section{Discussion and Suggestions}

The results of propagation analysis indicate that the occurrence probability of the PPRR is relatively high, which has been supported by Jiang et al. [42], who deemed that the resource conflict risk is the most crucial risk in construction enterprise management. This finding demonstrates the necessity to manage and monitor the resource risk. It can be concluded from the results of sensitivity 


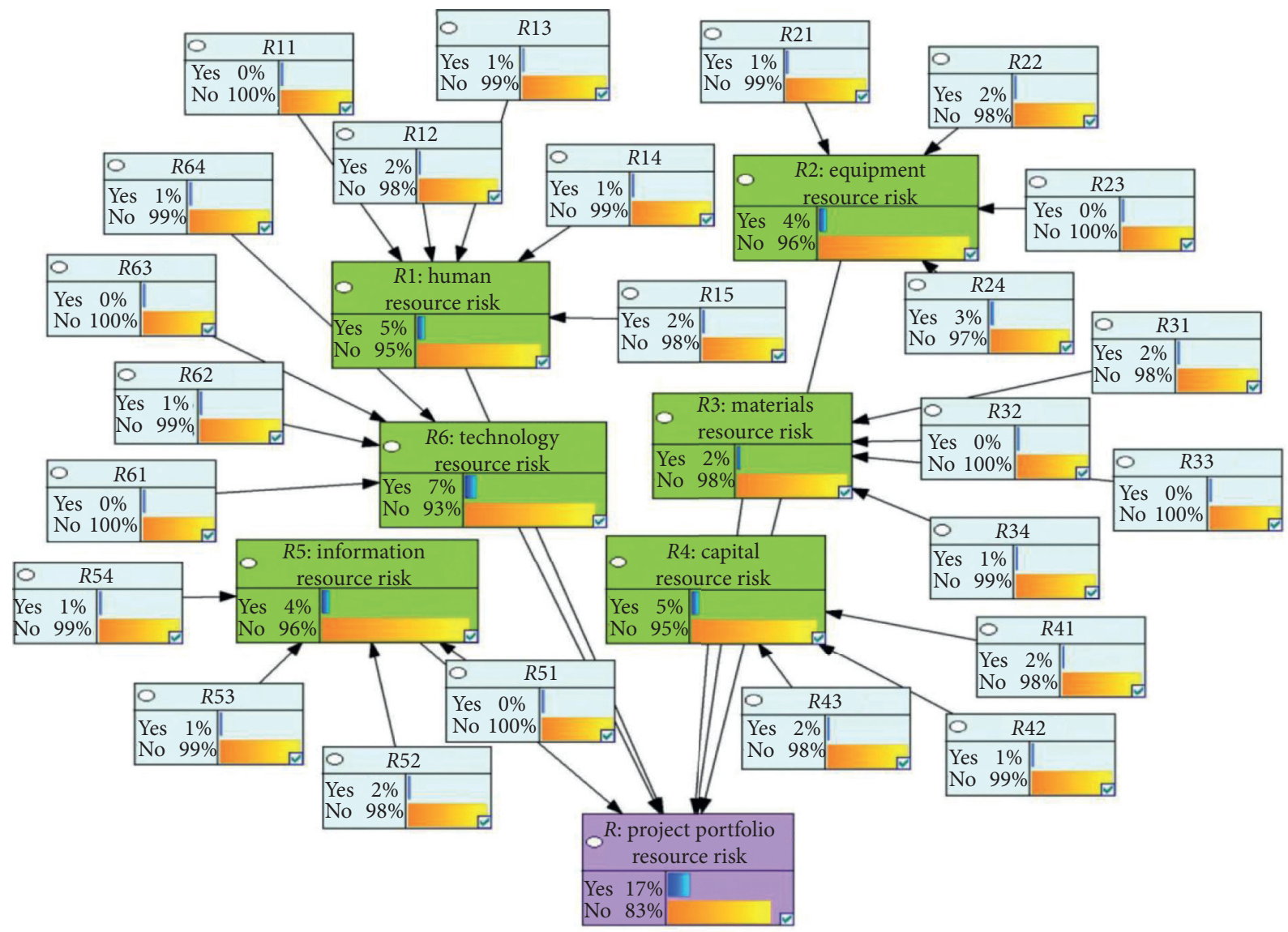

FIGURE 3: Forward propagation analysis of the project portfolio resource risk.

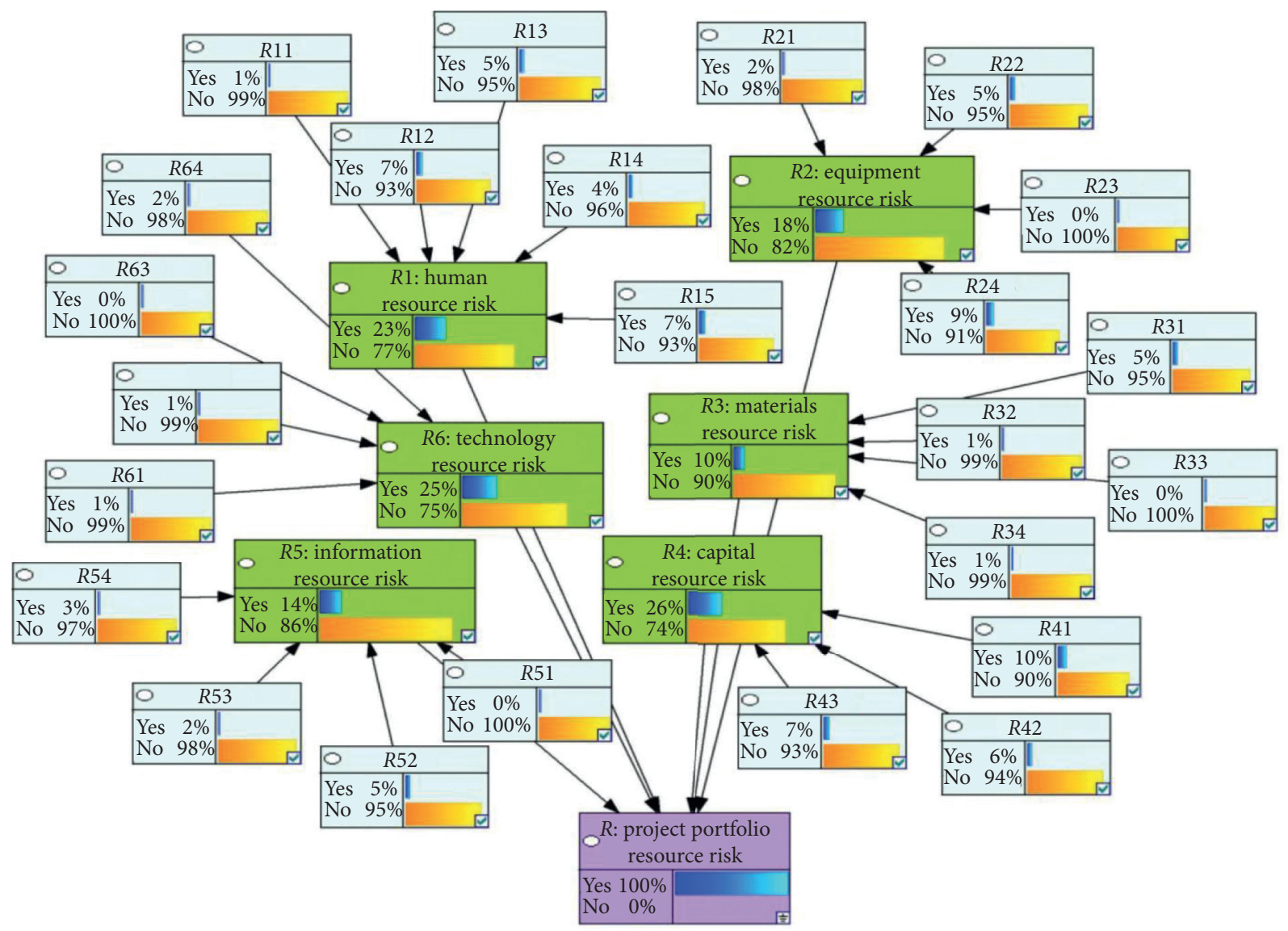

FIGURE 4: Backward propagation analysis of the project portfolio resource risk. 
Sensitivity for $R=$ yes

Current value: 0.173716 Reachable range: [0.170203 .. 0.176836]

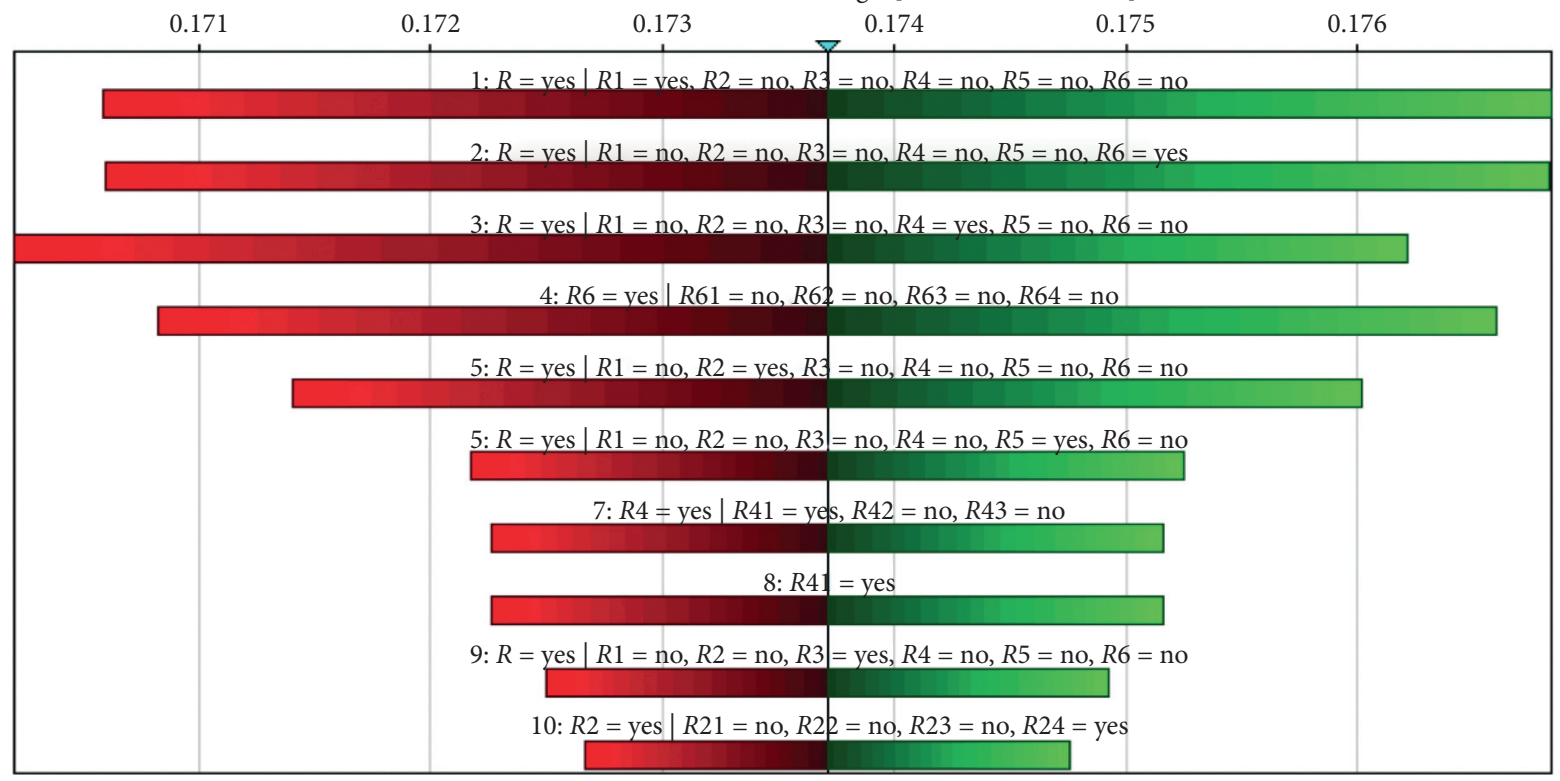

(a)

Sensitivity for $R=$ no

Current value: 0.826284 Reachable range: [0.823164 .. 0.829797]

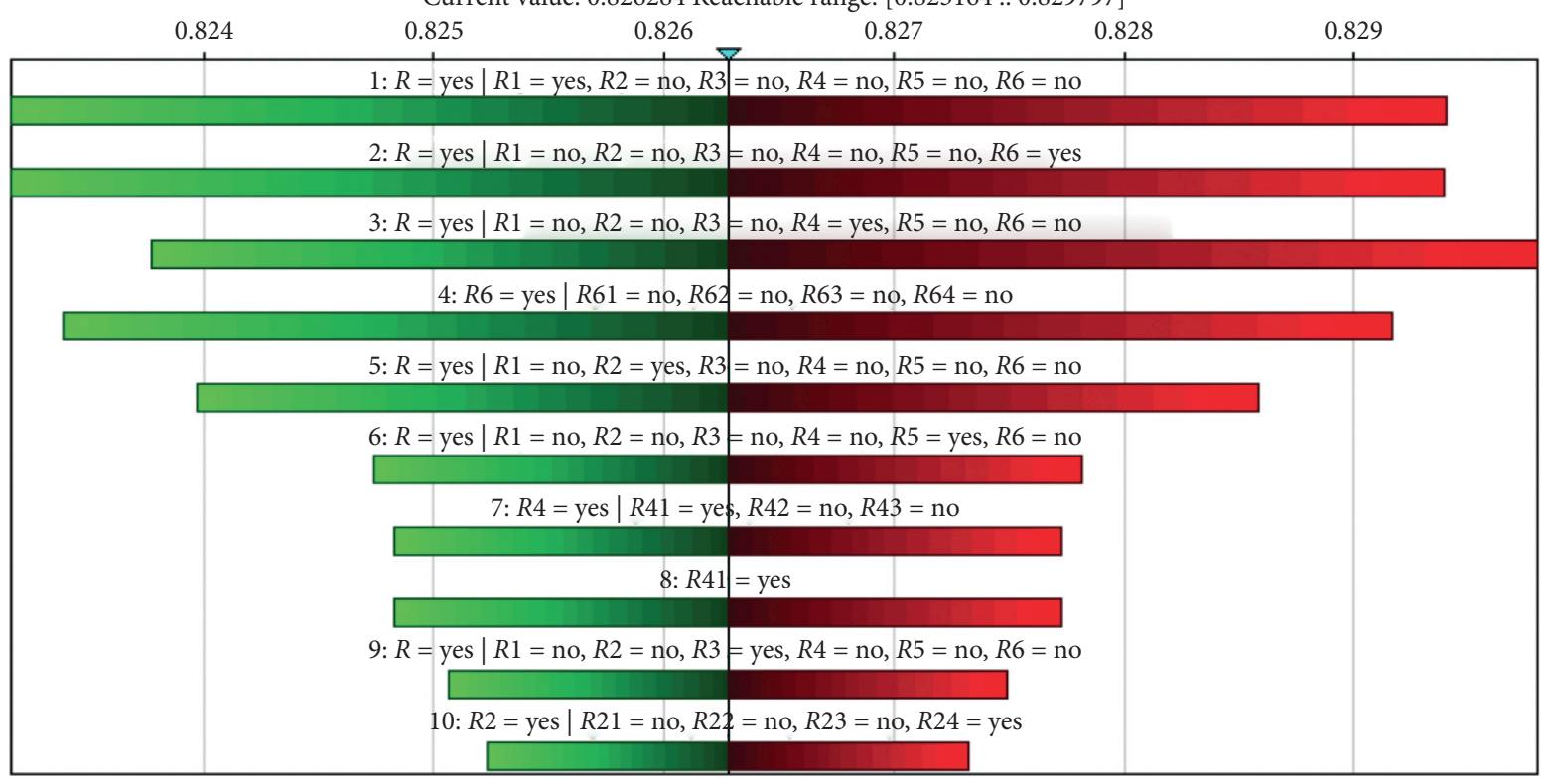

(b)

FIGURE 5: Sensitivity analysis of the project portfolio resource risk. (a) PPRR= "yes" state. (b) PPRR = "no" state.

analysis that "poor communication and cooperation among projects (R15)," "capital difficulty $(R 41)$, , and "lack of sharing technology among projects (R64)" are the contributing factors of the PPRR. Thus, this section discusses the importance of PPRR assessment in terms of these three key risk factors and proposes corresponding suggestions for reducing the PPRR.
5.1. Poor Communication and Cooperation among Projects. "Poor communication and cooperation among projects (R15)" is a key risk factor for the PPRR. The lack of good communication and cooperation has been regarded as the main cause of failure of large-scale infrastructure projects [63]. In addition, cooperation is necessary to quickly acquire knowledge $[48,64]$. Project managers should spend most of their time 


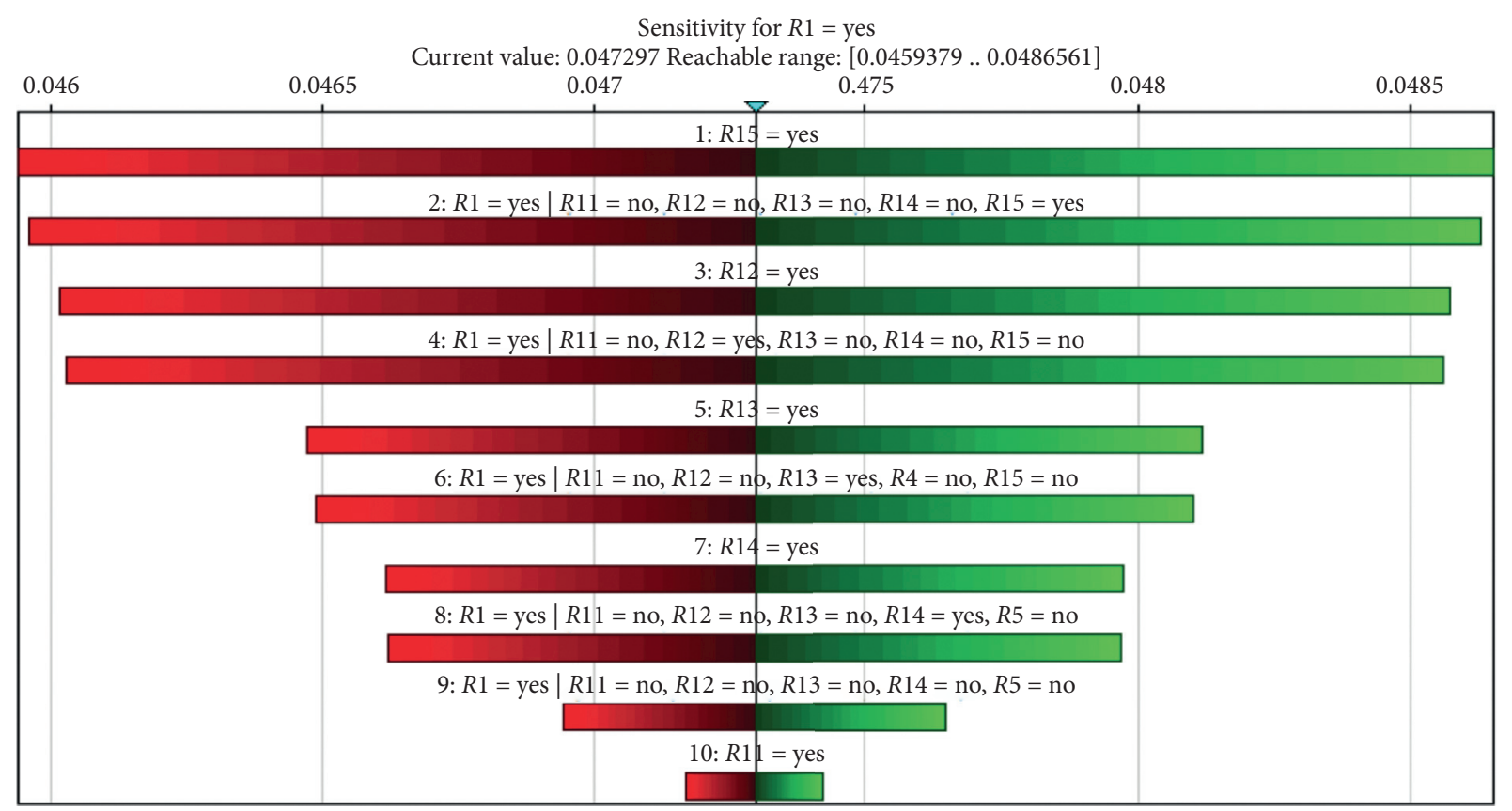

(a)

Sensitivity for $R 1=$ no

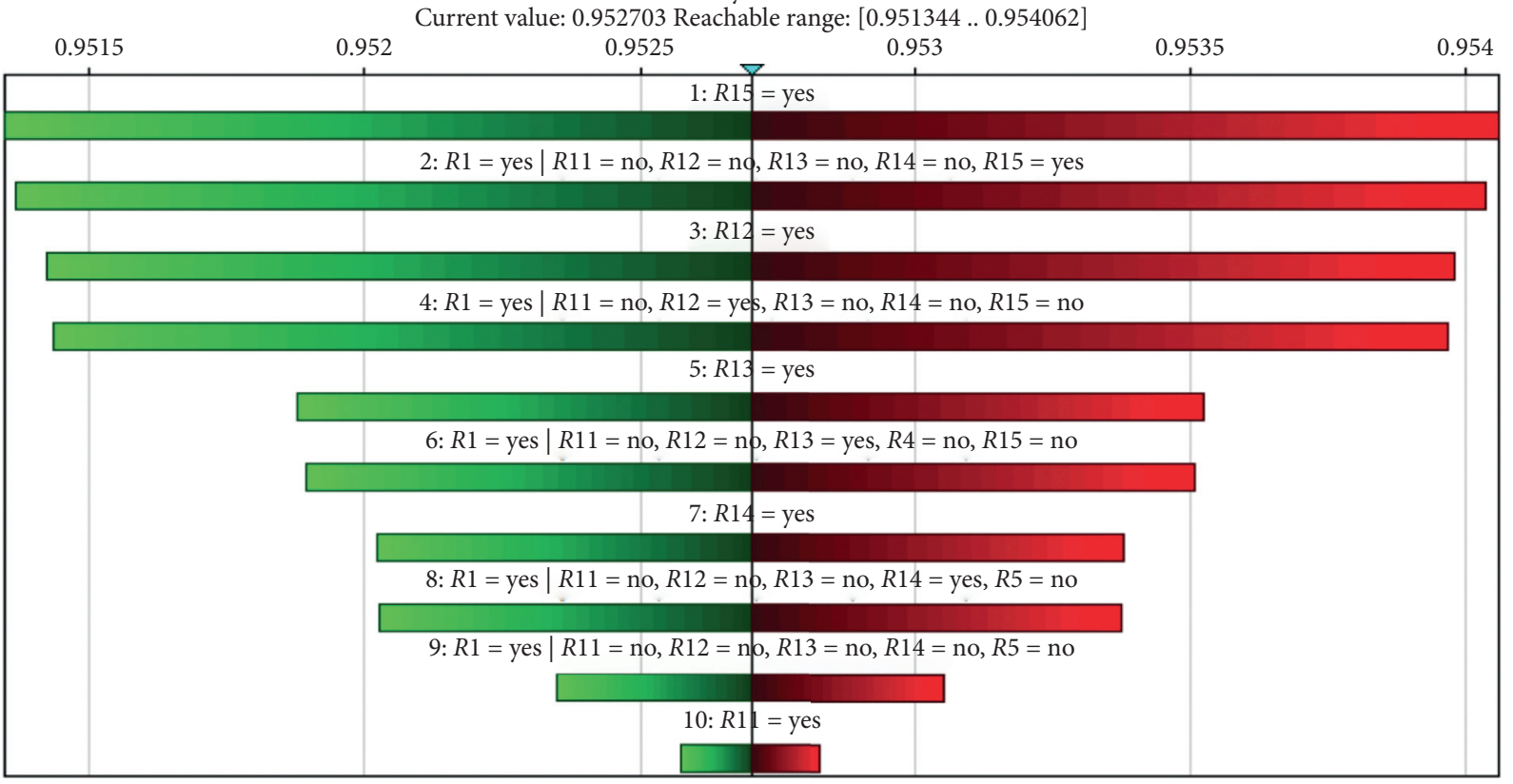

(b)

FIGURE 6: Sensitivity analysis of "human resource risk (R1)." (a) $R 1=$ "yes" state. (b) $R 1=$ "no" state.

communicating with team members and other project stakeholders and motivating team members to cooperate to ensure PP execution and outcome delivery [1]. Good communication can ensure the quality of project decisions and plans and coordinate stakeholder relationships to achieve project objectives. However, poor communication and cooperation are common problems that exist in almost every enterprise. The more complicated the organizational structure of an enterprise is, the more difficult its internal communication and cooperation are. Especially for the PP, multiple projects and project interdependency make the organizational structure more complex. Poor communication and cooperation among projects may affect the smooth implementation of the entire $\mathrm{PP}$, which shows the importance of communication in the PP. 
Sensitivity for $R 4=$ yes

Current value: 0.0476544 Reachable range: [0.045851 .. 0.0494578]

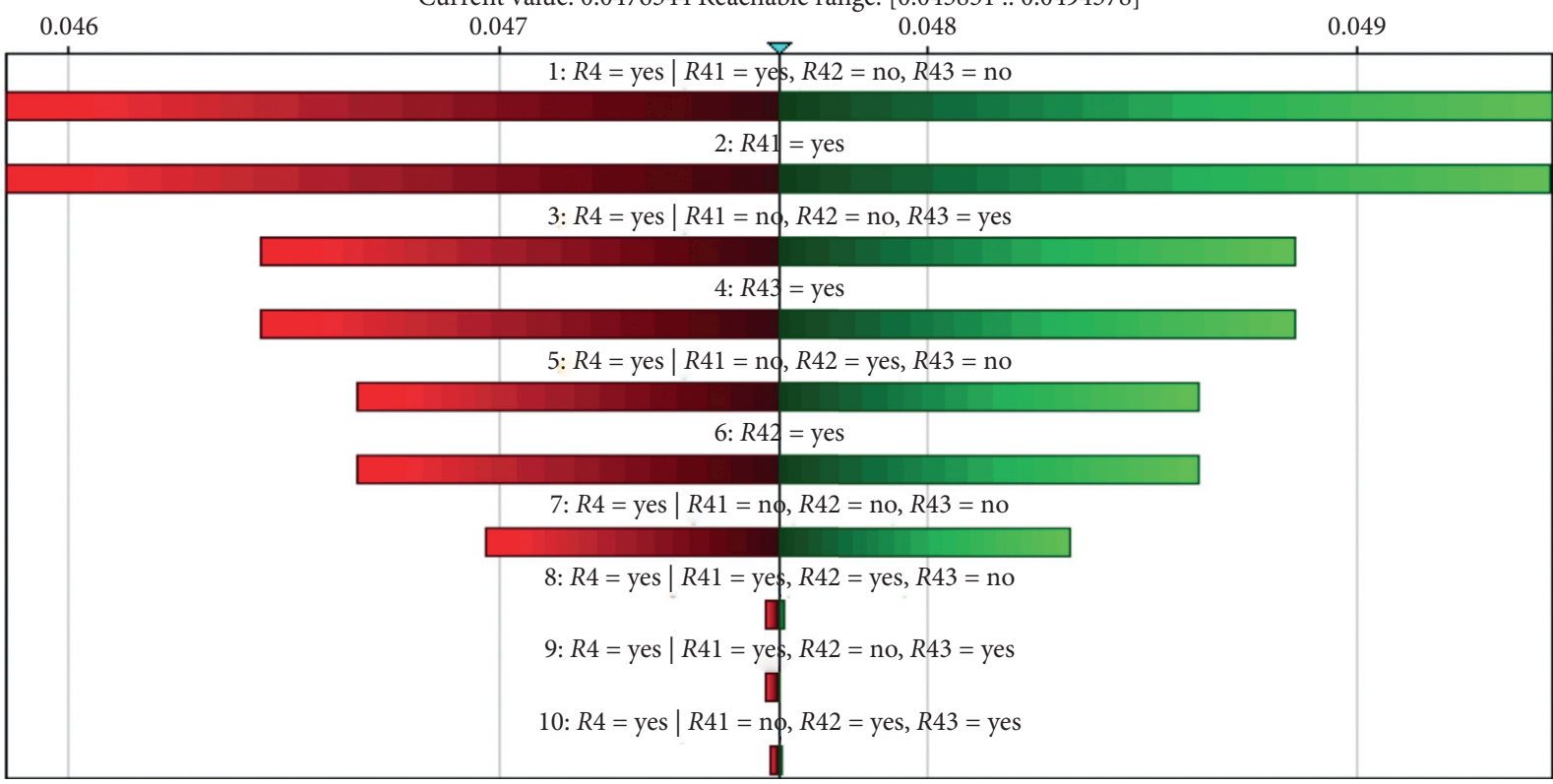

(a)

Sensitivity for $R 4=$ no

Current value: 0.952346 Reachable range: $\left[\begin{array}{lll}0.950542 & 0.954149\end{array}\right]$

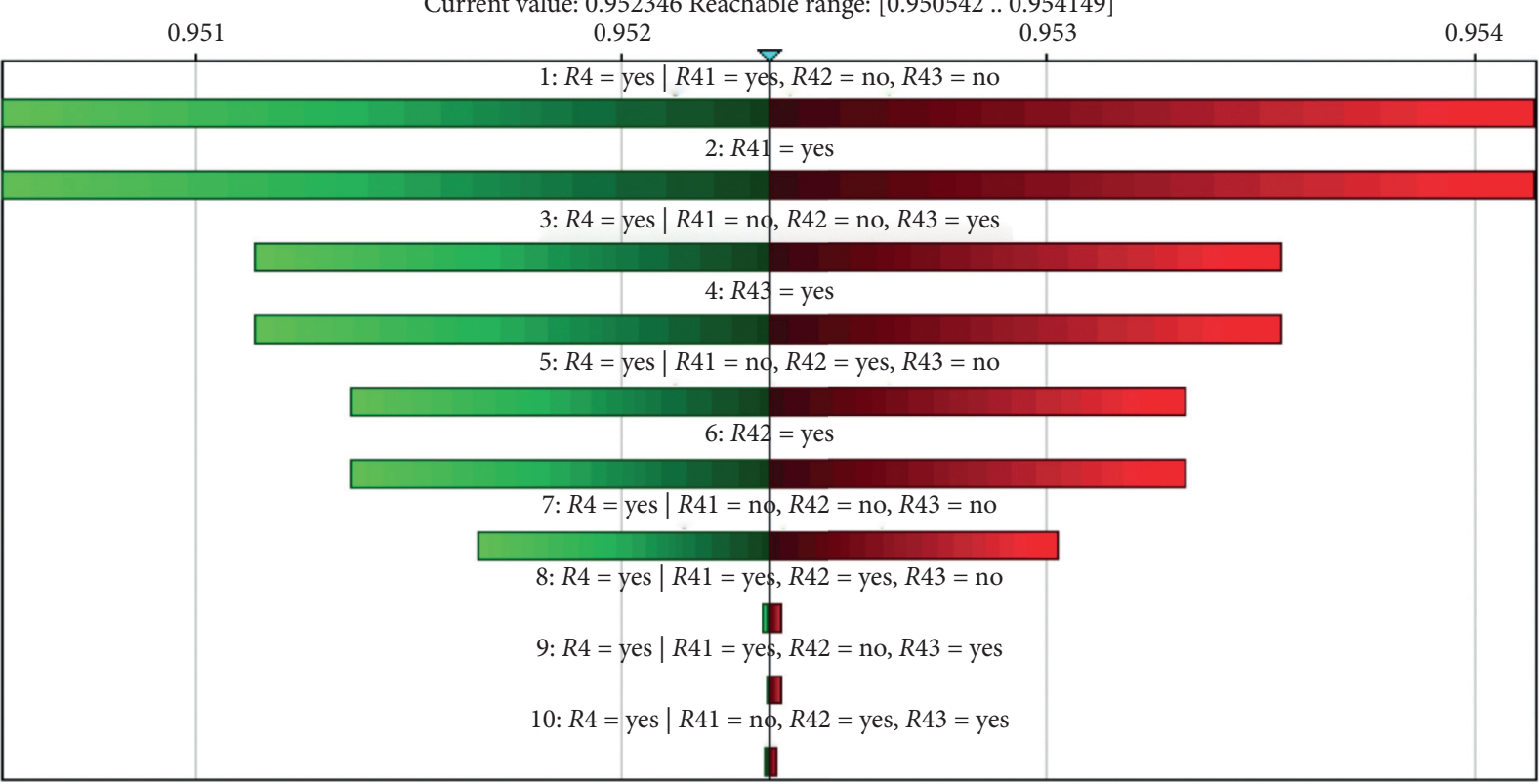

(b)

FIGURE 7: Sensitivity analysis of "capital resource risk (R4)." (a) $R 4=$ "yes" state. (b) $R 4=$ "no" state.

5.2. Capital Difficulty. As a critical risk factor for the PPRR, "capital difficulty (R41)" has attracted the attention of scholars. Many scholars have found that capital difficulty is the critical cause of delays in construction projects [63, 65], which indicates that the favorable implementation of projects depends on the guarantee of capital sources. Capital is the source for enterprises to purchase assets required for production and operation activities. A project may be infeasible if its actual capital needs exceed the capital allocated by the enterprise [66]. Especially for some small- and medium-size enterprises with insufficient financing capacity, capital difficulty will hinder their normal operations [67]. For a PP managed by a single enterprise, the smooth implementation of multiple projects requires sufficient 
Sensitivity for $R 6$ = yes

Current value: 0.0714801 Reachable range: [0.0652238 .. 0.0777364]

07

1: R6 = yes $\mid R 61=$ no, R62 = no, R63 = no, R64 = no

2: $R 6=$ yes $\mid R 61=$ no, $R 62=$ no, $R 63=$ no, $R 64=$ yes

3: $R 64=$ yes

5: $R 6=$ yes $\mid R 61=$ no, $R 62 \mid=$ yes, $R 63=$ no, $R 64=$ no

5: $R 6=$ yes $\mid R 61=$ yes, $R 6=$ no, $R 63=$ no, $R 64=$ no

6: $R 61=$ yes



7: $R 62=$ yes

8: $R 6=$ yes $\mid R 61=$ no, $R 62=$ no, $R 63=$ yes, $R 64=$ no

9: $R 63=$ yes

10: $R 6=$ yes $\mid R 61=$ no, $R 62=$ yes, $R 63=$ yes, $R 64=$ yes

(a)

Sensitivity for $R 6=$ no

Current value: 0.92852 Reachable range: [0.922264 0.934776$]$

0.925

0.93

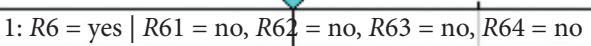

2: $R 6=$ yes $\mid R 61=$ no, $R 62 \mid=$ no, $R 63=$ no, $R 64=$ yes

3: $R 64=$ yes

5: $R 6=$ yes $\mid R 61=$ no, $R 62 \mid=$ yes, $R 63=$ no, $R 64=$ no

5: $R 6=$ yes $\mid R 61=$ yes, $R 62=$ no, $R 63=$ no, $R 64=$ no

6: $R 61=$ yes

$7: R 62=y e$

8: $R 6=$ yes $\mid R 61=$ no, $R 62 \mid=$ no, $R 63=$ yes, $R 64=$ no

9: $R 63=$ yes

10: $R 6=$ yes $\mid R 61=$ no, $R 62=$ yes, $R 63=$ yes, $R 64=$ yes

(b)

FIgURE 8: Sensitivity analysis of "technology resource risk (R6)." (a) R6= "yes" state. (b) R6= "no" state.

TABLE 10: Risk reassessment results of $R$.

$R$ (initial probability $=0.17372$ )

\begin{tabular}{ccccccc} 
& $R 1=0$ & $R 2=0$ & $R 3=0$ & $R 4=0$ & $R 5=0$ & $R 6=0$ \\
\hline$R=0$ & 0.13972 & 0.14873 & 0.16045 & 0.13526 & 0.15716 & 0.14071
\end{tabular}

capital guarantees. Moreover, multiple projects in a PP are interwoven, and the schedule delay caused by capital difficulty of previous projects will affect the progress of subsequent projects, thus slowing down the delivery of the whole PP. It is necessary to ensure sources of capital. 
TABLE 11: Risk reassessment results of $R 1, R 4$, and $R 6$.

\begin{tabular}{llllll}
\hline \multicolumn{5}{c}{$R 1$ (initial probability $=0.04730)$} \\
\hline $\mathrm{P}(R 1)$ & $R 11=0$ & $R 12=0$ & $R 13=0$ & $R 14=0$ & $R 15=0$ \\
& 0.04600 & 0.03447 & 0.03906 & 0.04047 & 0.03371 \\
& $R 41=0$ & $R 4$ (initial probability $=0.04765)$ & \\
$\mathrm{P}(R 4)$ & 0.02964 & 0.03785 & 0.03557 & \\
& \multicolumn{5}{c}{$R 6$ (initial probability $=0.07148)$} \\
& $R 61=0$ & $R 62=0$ & $R 63=0$ & $R 64=0$ \\
$\mathrm{P}(R 6)$ & 0.06974 & 0.06975 & 0.07115 & 0.06773 \\
\hline
\end{tabular}

TABLE 12: The posterior probability of risk factors according to $\beta$-values.

\begin{tabular}{|c|c|c|c|c|c|c|}
\hline \multirow{2}{*}{ Risk categories } & \multirow{2}{*}{ Risk factor } & \multicolumn{5}{|c|}{$\beta$-coefficients } \\
\hline & & 0.1 & 0.3 & 0.5 & 0.7 & 0.9 \\
\hline \multirow{6}{*}{$R$} & $R 4$ & 25 & 26 & 26 & 26 & 26 \\
\hline & $R 6$ & 23 & 24 & 25 & 25 & 26 \\
\hline & $R 1$ & 23 & 23 & 23 & 23 & 23 \\
\hline & $R 2$ & 21 & 19 & 18 & 17 & 16 \\
\hline & $R 5$ & 14 & 14 & 14 & 13 & 13 \\
\hline & $R 3$ & 10 & 10 & 10 & 10 & 10 \\
\hline \multirow{5}{*}{$R 1$} & $R 15$ & 8 & 7 & 7 & 7 & 7 \\
\hline & $R 12$ & 7 & 7 & 7 & 7 & 8 \\
\hline & $R 13$ & 5 & 5 & 5 & 5 & 5 \\
\hline & $R 14$ & 4 & 4 & 4 & 4 & 4 \\
\hline & $R 11$ & 1 & 1 & 1 & 1 & 1 \\
\hline \multirow{4}{*}{$R 2$} & $R 24$ & 11 & 10 & 9 & 8 & 7 \\
\hline & $R 22$ & 6 & 5 & 5 & 5 & 5 \\
\hline & $R 21$ & 2 & 2 & 2 & 2 & 2 \\
\hline & $R 23$ & 0 & 0 & 0 & 0 & 0 \\
\hline \multirow{4}{*}{$R 3$} & $R 31$ & 5 & 5 & 5 & 5 & 5 \\
\hline & $R 34$ & 1 & 1 & 1 & 1 & 1 \\
\hline & $R 32$ & 1 & 1 & 1 & 1 & 1 \\
\hline & $R 33$ & 0 & 0 & 0 & 0 & 0 \\
\hline \multirow{3}{*}{$R 4$} & $R 41$ & 10 & 10 & 10 & 10 & 10 \\
\hline & $R 43$ & 7 & 7 & 7 & 7 & 7 \\
\hline & $R 42$ & 7 & 6 & 6 & 6 & 5 \\
\hline \multirow{4}{*}{ R5 } & $R 52$ & 6 & 6 & 5 & 5 & 5 \\
\hline & R54 & 3 & 3 & 3 & 2 & 2 \\
\hline & $R 53$ & 2 & 2 & 2 & 2 & 2 \\
\hline & $R 51$ & 0 & 0 & 0 & 0 & 0 \\
\hline \multirow{4}{*}{$R 6$} & $R 64$ & 2 & 2 & 2 & 2 & 2 \\
\hline & $R 61$ & 1 & 1 & 1 & 1 & 1 \\
\hline & $R 62$ & 1 & 1 & 1 & 1 & 1 \\
\hline & $R 63$ & 0 & 0 & 0 & 0 & 0 \\
\hline
\end{tabular}

5.3. Lack of Sharing Technology among Projects. The results indicate that "lack of sharing technology among projects (R64)" is an important risk factor for the PPRR, and this finding can be supported by the research of Chambers [68], who perceived lack of knowledge sharing as a factor affecting the successful implementation of a project. Technology sharing, as a form of knowledge sharing, refers to the exchange and sharing of technology between different projects and departments to save capital costs and create more wealth. However, the direction of technology transmission is generally from top to bottom, and personnel at lower levels only obey and cannot participate in communication and discussion. In addition, the personnel at each level are confined to a narrow scope and have few opportunities to contact each other, which hinder technology sharing. For a PP, each project is managed separately and carries a certain substrategic objective. If a project fails to achieve the substrategic objective due to lack of technology, the realization of the strategic goal of the entire PP will be affected. Therefore, ensuring technology sharing among projects is conducive to the implementation of PP strategic objectives and the success of the PP.

5.4. Suggestions for Reducing the PPRR. Based on the above findings, special risk-reduction strategies can be proposed to reduce the risk level and prevent the occurrence of the PPRR:

(1) Improving communication and coordination: achieving good communication and cooperation can ensure a high degree of unity of thought and coordination among team members and achieve the continuous exchange of knowledge flow among projects [69, 70]. Good communication can be achieved by (a) formulating clear enterprise communication policies and improving communication systems; (b) establishing a communication platform among team members; and (c) establishing a special enterprise communication organization to ensure that team members can maintain communication and cooperation, thereby realizing the successful implementation of the PP.

(2) Broadening capital sources: if enterprises want to improve the efficiency of capital management in a PP, they need to build a scientific and reasonable capital structure and constantly enrich financing methods. On the one hand, enterprises can take active measures to encourage other powerful enterprises to participate in PP investment as investors. On the other hand, enterprises can improve the efficiency of capital use, reduce capital occupancy, and provide sufficient capital guarantees for the production and operation of the PP.

(3) Establishing an information network for knowledge sharing: an applicable information network is a bridge for team members to share knowledge, including technology, with others. Enterprises can develop knowledge management systems to establish knowledge-sharing information networks, thereby effectively encoding and transferring knowledge to promote the extensive exchange of knowledge within the PP. 


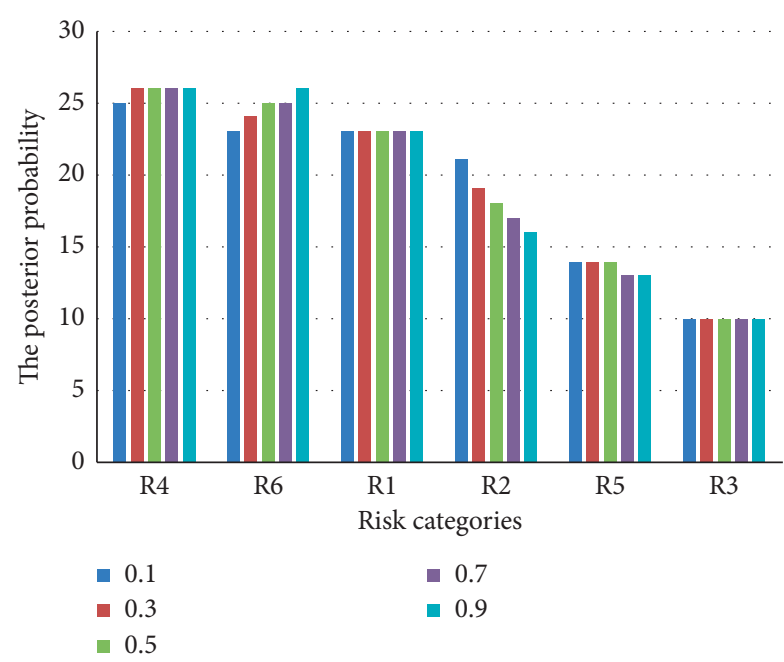

(a)

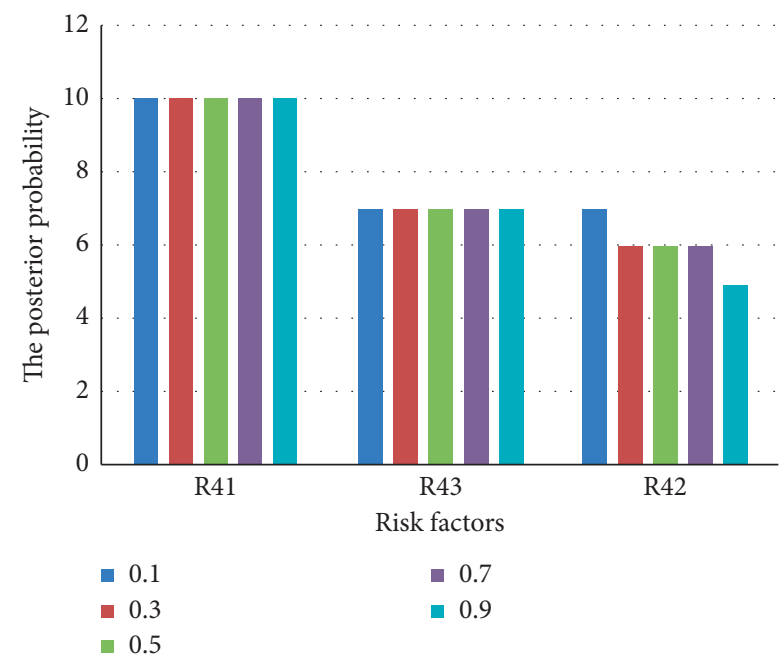

(c)

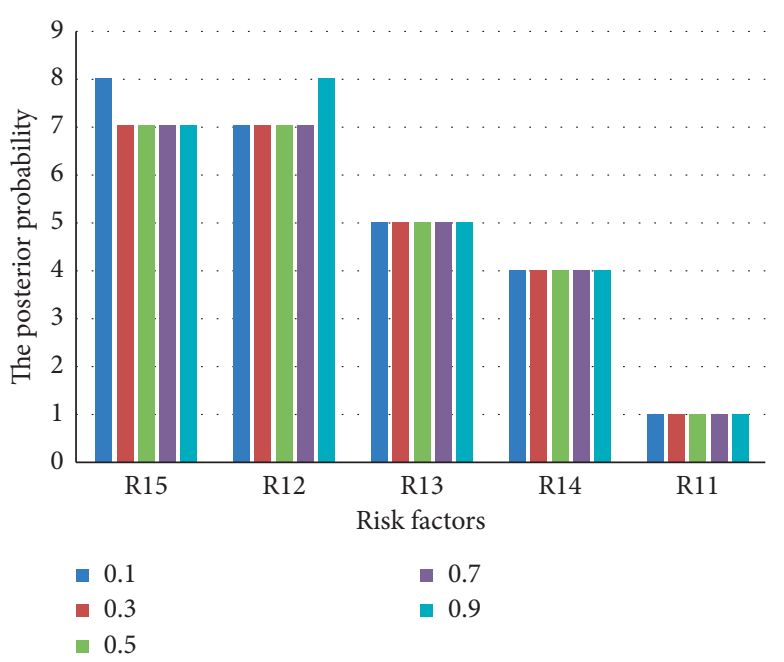

(b)

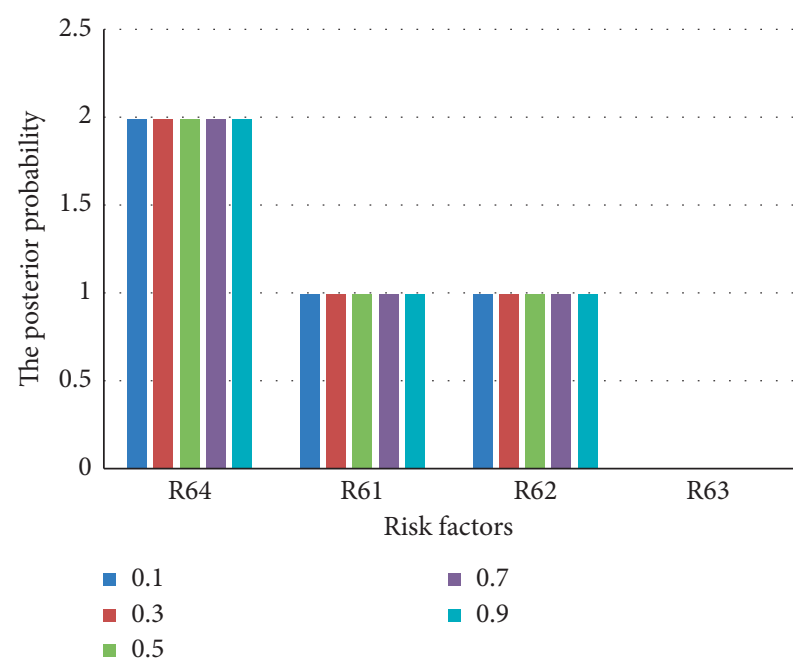

(d)

FIgURE 9: Sensitivity analysis according to the $\beta$-coefficient.

\section{Conclusions}

Due to project interdependency, evaluating PPRR caused by multiple projects' sharing or competing for specific resources has become an urgent problem. However, the complexities and uncertainties existing in a PP make it challenging to perform a reliable PPRR assessment. To address this issue, this paper applies an FBN model for systematically assessing PPRR and identifying critical risk factors. The BN is built based on identified risk factors considering project interdependency. Domain expert knowledge is employed to estimate the occurrence probabilities of all risk factors. A numerical analysis demonstrates that the occurrence probability of the PPRR is relatively high. In addition, the results reveal that "poor communication and cooperation among projects," "capital difficulty," and "lack of sharing technology among projects" are mainly responsible for the PPRR. The findings provide a reference for project managers to adopt corresponding risk-reduction strategies. The main contributions of this paper can be summarized both theoretically and practically. Theoretically, project interdependency is considered in identifying resource risk factors, which further deepens the research on PPRR assessment. Furthermore, the application of the FBN model in PPRR assessment broadens the research of the FBN in the PP domain. Exploration of PPRR contributes to the body of knowledge of systematic PP risk management from a resource category perspective. Little is currently known about the contributing factors of the resource risk during the implementation of the $\mathrm{PP}$. To further avoid and control the PPRR, the trigger must be determined and quantified. This research analyzes the critical risk factors leading to PPRR, which makes PPRR assessment more effective. Practically, it emphasizes that project managers should put in place a specific PPRR management plan that pays very detailed attention to project interdependency. This means that resource management needs to consider both the characteristics of the project itself and the project interdependency. Besides, it is vital for project managers to reduce the PPRR by adopting targeted strategies. From the macro point of view, more attention should be paid to human, 
capital, and technology resource risks because their effects on PPRR are larger than others. From the micro point of view, the risk factors with higher probability under the above three resource risks need to be focused on. Based on the risk factors with higher probability in the above three resource risks, riskreduction strategic decisions can be made, which provide a reference for project managers to make reasonable management decisions.

According to systematic and representative principles, the risk factors affecting the PPRR in this paper are selected from the perspective of resource categories by a literature review. Due to the restriction of objective conditions, there may be other risk factors affecting the PPRR. For our future work, more risk factors (such as organizational factors and environmental factors) could be considered based on this research. Furthermore, the main purpose of this paper is to identify the critical resource categories that cause PPRR and then to avoid PPRR by controlling the key risk factors under the critical resource categories. Thus, the interaction relationships among risk factors are not considered. As a direction for future study, integration of the $\mathrm{BN}$ with the design structure matrix (DSM) or other methods for judging the relationships among risk factors can be performed to analyze risk interaction.

\section{Data Availability}

The initial data of each project used to support the findings of this study are included within the article.

\section{Conflicts of Interest}

The authors declare that there are no conflicts of interest regarding the publication of this paper.

\section{Acknowledgments}

The authors wish to express appreciation to the participants and interviewees of this study. This work was supported by the National Natural Science Foundation of China (Grant no. 72002018), the Ministry of Education Humanities and Social Sciences Fund (Grant no. 17XJC630001), Innovation Capacity Support Plan of Shaanxi Province (Grant no. 2020KJXX-054), Major Projects of Shaanxi Social Science Federation (Grant no. 2020Z361), the Social Science Planning Fund of Xi'an (Grant no. JG207), the Soft Science Foundation of Xi'an (Grant no. 2019111813RKX002SF0065), the Fundamental Research Funds for the Central Universities (Grant nos. 300102238620 and 300102230613 ), and Social Science Planning Fund of Shaanxi Province (Grant no. 2020R028).

\section{References}

[1] Project Management Institute, A Guide To The Project Management Body of Knowledge (PMBOK ${ }^{\circledR}$ Guide), Vol. 44, Project Management Institute, Newtown Square, PA, USA, 5th edition, 2013.

[2] L. S. Cardona-meza and G. Olivar-tost, "Modeling and simulation of project management through the PMBOK D standard using complex networks," Complexity, vol. 2017, Article ID 4791635, 12 pages, 2017.

[3] Z. Laslo and A. I. Goldberg, "Resource allocation under uncertainty in a multi-project matrix environment: is organizational conflict inevitable?" International Journal of Project Management, vol. 26, no. 8, pp. 773-788, 2008.

[4] D. Guan, P. Guo, K. W. Hipel, and L. Fang, "Risk reduction in a project portfolio," Journal of Systems Science and Systems Engineering, vol. 26, no. 1, pp. 3-22, 2017.

[5] N. Parolia, J. J. Jiang, G. Klein, and T. S. Sheu, "The contribution of resource interdependence to IT program performance: a social interdependence perspective," International Journal of Project Management, vol. 29, no. 3, pp. 313-324, 2011.

[6] S. Song, F. Yang, and Q. Xia, "Multi-criteria project portfolio selection and scheduling problem based on acceptability analysis," Computers and Industrial Engineering, vol. 135, pp. 793-799, 2019.

[7] M. Abimbola, F. Khan, and N. Khakzad, "Dynamic safety risk analysis of offshore drilling," Journal of Loss Prevention in the Process Industries, vol. 30, pp. 74-85, 2014.

[8] X. Li, G. Chen, and H. Zhu, "Quantitative risk analysis on leakage failure of submarine oil and gas pipelines using Bayesian network," Process Safety and Environmental Protection, vol. 103, pp. 163-173, 2016.

[9] Y. Y. Wee, W. P. Cheah, S. C. Tan, and K. Wee, "A method for root cause analysis with a Bayesian belief network and fuzzy cognitive map," Expert Systems with Applications, vol. 42, no. 1, pp. 468-487, 2015.

[10] E. Zarei, M. Yazdi, R. Abbassi, and F. Khan, "A hybrid model for human factor analysis in process accidents: FBN-HFACS," Journal of Loss Prevention in the Process Industries, vol. 57, pp. 142-155, 2019.

[11] Y. Zhong, Z. Chen, Z. Zhou, and H. Hu, "Uncertainty analysis and resource allocation in construction project management," Engineering Management Journal, vol. 30, no. 4, pp. 293-305, 2018.

[12] M. Park, "Model-based dynamic resource management for construction projects," Automation in Construction, vol. 14, no. 5, pp. 585-598, 2005.

[13] T. Korhonen, T. Laine, and M. Martinsuo, "Management control of project portfolio uncertainty: a managerial role perspective," Project Management Journal, vol. 45, no. 1, pp. 21-37, 2014.

[14] A. Söderholm, "Project management of unexpected events," International Journal of Project Management, vol. 26, no. 1, pp. 80-86, 2008.

[15] J. Tian, X. Hao, and M. Gen, "A hybrid multi-objective EDA for robust resource constraint project scheduling with uncertainty," Computers \& Industrial Engineering, vol. 130, no. 8, pp. 317-326, 2019.

[16] R. Nemati-lafmejani, H. Davari-ardakani, and H. Najafzad, "Multi-mode resource constrained project scheduling and contractor selection: mathematical formulation and metaheuristic algorithms," Applied Soft Computing, vol. 81, p. 105533, 2019.

[17] N. Balouka and I. Cohen, "A robust optimization approach for the multi-mode resource-constrained project scheduling problem," European Journal of Operational Research, 2019.

[18] K. Yaghootkar and N. Gil, "The effects of schedule-driven project management in multi-project environments," International Journal of Project Management, vol. 30, no. 1, pp. 127-140, 2012. 
[19] M. A. Kaulio, "Project leadership in multi-project settings: findings from a critical incident study," International Journal of Project Management, vol. 26, no. 4, pp. 338-347, 2008.

[20] D. Fedyanin, "Resource allocation mechanisms for the portfolio of projects with concave utility functions," in Proceedings of the 2019 IEEE 21st Conference on Business Informatics, CBI 2019, vol. 2, pp. 77-82, Moscow, Russia, July 2019.

[21] M. Zhang, H. Chen, and J. Liu, "Resource allocation approach to associate business-IT alignment to enterprise architecture design," Journal of Systems Engineering and Electronics, vol. 30, no. 2, pp. 343-351, 2019.

[22] S. Zhang and Y. He, "The analysis of resource conflicts based on hawk and dove game in multi-projects management," in Proceedings 2012 5th International Joint Conference on Computational Sciences and Optimization CSO 2012, pp. 702-705, Harbin, China, June 2012.

[23] C. Liu, J. Cheng, Y. Wang, and S. Gao, "Time performance optimization and resource conflicts resolution for multiple project management," IEICE Transactions on Information and Systems, vol. E99.D, no. 3, pp. 650-660, 2016.

[24] F. Li and Z. Xu, "A multi-agent system for distributed multiproject scheduling with two-stage decomposition," PLoS One, vol. 13, no. 10, pp. 1-24, 2018.

[25] Y. Hu, X. Zhang, E. W. T. Ngai, R. Cai, and M. Liu, "Software project risk analysis using Bayesian networks with causality constraints," Decision Support Systems, vol. 56, no. 1, pp. 439-449, 2013.

[26] K.-S. Chin, D.-W. Tang, J.-B. Yang, S. Y. Wong, and H. Wang, "Assessing new product development project risk by Bayesian network with a systematic probability generation methodology," Expert Systems with Applications, vol. 36, no. 6, pp. 9879-9890, 2009.

[27] E. Lee, Y. Park, and J. G. Shin, "Large engineering project risk management using a Bayesian belief network," Expert Systems with Applications, vol. 36, no. 3, pp. 5880-5887, 2009.

[28] D. Guan and P. Guo, "Constructing interdependent risks network of project portfolio based on bayesian network," in Proceedings of the 2014 International Conference on Management Science \& Engineering 21th Annual Conferenc, pp. 1587-1592, Helsinki, Finland, October 2014.

[29] F. Ghasemi, M. Sari, V. Yousefi, R. Falsafi, and J. Tamošaitienè, "Project portfolio risk identification and analysis, considering project risk interactions and using bayesian networks," Sustainability, vol. 10, no. 5, p. 1609, 2018.

[30] M. M. Aliabadi, H. Aghaei, O. Kalatpour, and A. R. Soltanian, "Analysis of human and organizational factors that influence mining accidents based on Bayesian network," International Journal of Occupational Safety and Ergonomics, vol. 24, pp. 1-16, 2018.

[31] N. Zahra, S. Mortazavi, A. Hassan, and H. Ebrahim, "Ranking the occupational incident contributory factors: a Bayesian network model for the petroleum industry," Process Safety and Environmental Protection, vol. 137, pp. 352-357, 2020.

[32] I. Mohammadfam, F. Ghasemi, O. Kalatpour, and A. Moghimbeigi, "Constructing a Bayesian network model for improving safety behavior of employees at workplaces," Applied Ergonomics, vol. 58, pp. 35-47, 2017.

[33] H. Zerrouki and H. Smadi, "Bayesian belief network used in the chemical and process industry: a review and application," Journal of Failure Analysis and Prevention, 2016.

[34] M. Javadi, G. Saeedi, and K. Shahriar, "Developing a new probabilistic approach for risk analysis, application in underground coal mining," Journal of Failure Analysis and Prevention, vol. 17, no. 5, pp. 989-1010, 2017.
[35] J. Ren, I. Jenkinson, J. Wang, D. L. Xu, and J. B. Yang, "An offshore risk analysis method using fuzzy bayesian network," Journal of Offshore Mechanics and Arctic Engineering, vol. 131, no. 4, pp. 1-12, 2009.

[36] O. S. Fard and M. Ramezanzadeh, "On fuzzy portfolio selection problems: a parametric representation approach," Complexity, pp. 1-12, 2017.

[37] R. Viertl, "Is it necessary to develop a fuzzy bayesian inference?" Probability and Bayesian Statistics, Springer, Boston, MA, USA, pp. 471-475, 1987.

[38] Q. Zhou, Y. D. Wong, H. S. Loh, and K. F. Yuen, “A fuzzy and Bayesian network CREAM model for human reliability analysis-the case of tanker shipping," Safety Science, vol. 105, pp. 149-157, 2018.

[39] E. Zarei, N. Khakzad, V. Cozzani, and G. Reniers, "Safety analysis of process systems using Fuzzy Bayesian Network (FBN)," Journal of Loss Prevention in the Process Industries, vol. 57, pp. 7-16, 2019.

[40] M. Li, D. Wang, and H. Shan, "Risk assessment of mine ignition sources using fuzzy Bayesian network," Process Safety and Environmental Protection, vol. 125, pp. 297-306, 2019.

[41] A. Azar and K. M. Dolatabad, "A method for modelling operational risk with fuzzy cognitive maps and Bayesian belief networks," Expert Systems with Applications, vol. 115, pp. 607-617, 2019.

[42] X. Jiang, Y. Hu, W. Li, W. Hu, Y. Chen, and X. Zheng, "Risk assessment and prediction of resource conflict in hydropower engineering programmes from the perspective of construction enterprises," South-to-North Water Transfers and Water Science \& Technology, vol. 17, no. 5, pp. 202-208, 2019.

[43] W. Zhou, "A study of schedule risk of overseas construction projects based on resource constraint factor classification," Engineering Management Journal, vol. 33, no. 3, pp. 116-121, 2019.

[44] Project Management Institute, A Guide to the Project Management Body of Knowledge (PMBOK ${ }^{\circledR}$ Guide), Project Management Institute, Newtown Square, PA, USA, 6th edition, 2017.

[45] M. Hofman and G. Grela, "Project portfolio risk categorisation-factor analysis results," International Journal of Information Systems and Project Management, vol. 6, no. 4, pp. 39-58, 2018.

[46] M. Hofman, S. Spalek, and G. Grela, "Shedding new light on project portfolio risk management," Sustainability, vol. 9, no. 10, 2017.

[47] M. Hofman and G. Grela, "Taxonomy of the project portfolio risks-an empirical investigation," Procedia Computer Science, vol. 121, pp. 137-144, 2017.

[48] W. Guangdong and D. Z. Tang, "Inter-organizational cooperative innovation of project-based supply chains under consideration of monitoring signals," International Journal of Simulation Modelling, vol. 14, no. 3, pp. 539-550, 2015.

[49] V. W. Y. Tam and I. W. H. Fung, "A study of knowledge, awareness, practice and recommendations among Hong Kong construction workers on using personal respiratory protective equipment at risk," The Open Construction and Building Technology Journal, vol. 2, no. 1, pp. 69-81, 2008.

[50] C. S. Lim and M. Z. Mohamed, "Criteria of project success: an exploratory re-examination," International Journal of Project Management, vol. 17, no. 4, pp. 243-248, 1999.

[51] J. K. Larsen, G. Q. Shen, S. M. Lindhard, and T. D. Brunoe, "Factors affecting schedule delay, cost overrun, and quality level in public construction projects," Journal of Management in Engineering, vol. 32, no. 1, 2016. 
[52] S. Hannan and C. Sutherland, "Mega-projects and sustainability in Durban, South Africa: convergent or divergent agendas?” Habitat International, vol. 45, pp. 205-212, 2015.

[53] B. B. M. Keers and P. C. van Fenema, "Managing risks in public-private partnership formation projects," International Journal of Project Management, vol. 36, no. 6, pp. 861-875, 2018.

[54] L. M. Khodeir and M. Nabawy, "Identifying key risks in infrastructure projects-case study of Cairo Festival City project in Egypt," Ain Shams Engineering Journal, vol. 10, no. 3, pp. 613-621, 2019.

[55] Z. Sigmund and M. Radujković, "Risk breakdown structure for construction projects on existing buildings," Procedia Social and Behavioral Sciences, vol. 119, pp. 894-901, 2014.

[56] F. V. Jensen and T. D. Nielsen, Bayesian Network and Decision Graphs, Springer, New York, NY, USA, 2007.

[57] S.-J. Chen and C.-L. Hwang, Fuzzy Multiple Attribute Decision Making Methods, pp. 289-486, Springer, Berlin, Germany, 1992.

[58] T. A. Runkler and M. A. Glesner, "A set of axioms for defuzzification strategies towards a theory of rational defuzzification operators," in Proceedings of the IEEE International Conference on Fuzzy Systems, San Francisco, CA, USA, March-April 1993.

[59] T. Onisawa, "An application of fuzzy concepts to modelling of reliability analysis," Fuzzy Sets and Systems, vol. 37, no. 3, pp. 267-286, 1990.

[60] J. Pitchforth and K. Mengersen, "A proposed validation framework for expert elicited Bayesian Networks," Expert Systems with Applications, vol. 40, no. 1, pp. 162-167, 2013.

[61] W. Qiao, Y. Liu, X. Ma, and Y. Liu, "Human factors analysis for maritime accidents based on a dynamic fuzzy bayesian network," Risk Analysis, pp. 1-24, 2020.

[62] N. U. I. Hossain, F. Nur, S. Hosseini, R. Jaradat, M. Marufuzzaman, and S. M. Puryear, “"A Bayesian network based approach for modeling and assessing resilience : a case study of a full service deep water port," Reliability Engineering \& System Safety, vol. 189, pp. 378-396, 2019.

[63] W. Gao and K. Hong, "The portfolio balanced risk index model and analysis of examples of large-scale infrastructure project," Complexity, vol. 2017, pp. 1-13, 2017.

[64] W. Guangdong, "Project-Based Supply Chain Cooperative incentive based on reciprocity preference," International Journal of Simulation Modelling, vol. 13, no. 1, pp. 102-115, 2014.

[65] V. T. Luu, S.-Y. Kim, N. V. Tuan, and S. O. Ogunlana, "Quantifying schedule risk in construction projects using Bayesian belief networks," International Journal of Project Management, vol. 27, no. 1, pp. 39-50, 2009.

[66] A. Brahm, A. B. Hadj-alouane, and S. Sboui, "Dynamic and reactive optimization of physical and financial flows in the supply chain," International Journal of Industrial Engineering Computations, vol. 11, pp. 83-106, 2020.

[67] M. Protopappa-sieke and R. W. Seifert, "Benefits of working capital sharing in supply chains," Journal of the Operational Research Society, vol. 68, no. 5, pp. 521-532, 2017.

[68] A. B. Chambers, Evaluation of Work Injuries between Employment Types-A Study of the Oil and Gas Industry, Northcentral University, San Diego, CA, USA, 2015.

[69] W. Guangdong, "Knowledge collaborative incentive based on inter-organizational cooperative innovation of project-based supply chain," Journal of Industrial Engineering and Management, vol. 6, no. 4, pp. 1065-1081, 2013.
[70] G. Wu, J. Zuo, and X. Zhao, "Incentive model based on cooperative relationship in sustainable construction projects," Sustainability, vol. 9, no. 7, p. 1191, 2017. 